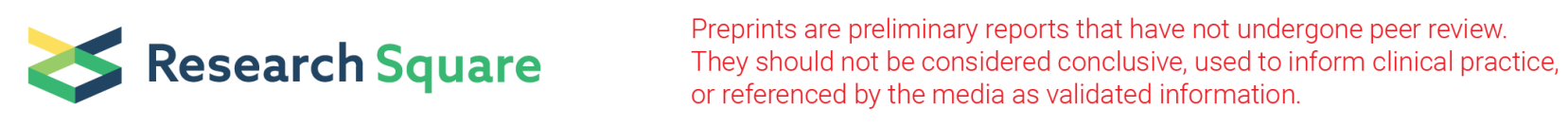

\title{
Initial Coin Offerings (ICOs): the importance of human capital
}

José Campino ( $\square$ jpmcampino@gmail.com )

ISCTE-Instituto Universitario de Lisboa

Ana Brochado

ISCTE-Instituto Universitario de Lisboa

Álvaro Rosa

ISCTE-Instituto Universitario de Lisboa

\section{Original Article}

Keywords: Initial Coin Offering (ICO), fintech, bank, financial services, technology, blockchain, human capital, innovation, venture capital, crowdfunding

Posted Date: February 9th, 2021

DOI: https://doi.org/10.21203/rs.3.rs-171187/v1

License: (c) (i) This work is licensed under a Creative Commons Attribution 4.0 International License. Read Full License

Version of Record: A version of this preprint was published at Journal of Business Economics on April 2nd, 2021. See the published version at https://doi.org/10.1007/s11573-021-01037-w. 


\section{Abstract}

The Initial Coin Offerings (ICOs) subject has been gaining relevance due to its novelty, due to the capital amounts involved in the projects, as well as the disruptive technology and methods involved. ICOs are a disruptive way to finance new projects which involve high risks and which are mainly technological. This way to finance a project has been compared to others, namely, crowdfunding, venture capital or Initial Public Offerings (IPOs). Nevertheless, ICOs have very specific characteristics which make them unique. We have studied the ICO projects and developed a literature review on the topic. Building on the Human Capital Theory (HCT), we have also studied the importance given to the project's team and its perceived impact on projects' success. Our contribution to fill in this literature gap was to develop an econometric model which measures the impact of team's characteristics on the success of a project. The database was collected with the combination of two data sources and is composed of 3158 profiles and 340 ICO projects. We have concluded that team variables are significant contributors to project's success. Our data suggests that people's location contributes to projects' success as well as promoters' networks. The ratings attributed by external parties to the project are also indicators of success. Several control variables such as the implementation of thresholds to investment, the number of currencies accepted, the platform in which the ICO is developed, the existence of bonus schemes and the year of the project were found to be statistically significant having an impact on projects' outcome.

\section{Introduction}

Traditional financing ways have been dominating the investment arena but new ways such as crowdfunding have been emerging. The technological developments allowed for even more disruptive financing methods to appear, namely, the Initial Coin Offerings (ICOs) (Mamonov \& Malaga, 2020). The ICOs are disruptive and based on blockchain technology allowing the investment via a token and not fiat currencies (Chiu \& Greene, 2019) eliminating both investment and geographic barriers and democratizing the access to investments (OECD, 2019). Although the similarities and the comparison done between ICOs and other financing forms such as crowdfunding, venture capital or Initial Public Offerings (IPOs) (OECD, 2019) the first have unique characteristics which distinguish them (Kranz, Nagel, \& Yoo, 2019). The success of the ICO projects has also been studied in the academic literature (Jong, Roosenboom, \& Kolk, 2018) but several gaps still exist (Chen \& Chen, 2020), for instance, a deeper study on the importance of the human capital on the success of projects (Fisch, 2019) since this factor has been considered to be relevant (Allison, Davis, Webb, \& Short, 2017; An, Duan, Hou, \& Xu, 2019). With this paper we aim to fill in the literature gap by analyzing the team's characteristics and understanding their impact on the project's outcome. We have created a database composed by 3158 profiles and 340 projects retrieved from a combination of two sources, namely, ICOBench and Linkedln. The database contains several information on the profiles and on the projects from which it was possible to create variables and integrate them in an econometric model. We have concluded that several team variables contribute to the success of a project, namely, the promoters' location, their networks, the size of the team and the ratings attributed to external parties concerning teams' aspects. Our data also suggests that characteristics related with promoters' education or professional experience do not play a relevant role defining the success of a project. Several control variables revealed to be significant contributors to the success of projects, namely, the implementation of thresholds to investment, the number of currencies accepted, the platform in which the ICO is developed, the existence of bonus schemes and the year of the project. Our research will start in section 3 with the literature review in which we will be focusing on the ICOs' main characteristics, perform a market snapshot, understand the advantages and disadvantages of the ICOs, clarify the ICOs' differentiation and lifecycle and understand the human capital importance in the projects. In section 4 we will explore the methodology used in the research and in section 5 we will present the results of our study starting with descriptive statistics followed by a correspondence analysis and the econometric model. We will conclude and discuss the results in section 6.

\section{Literature Review}

\subsection{Main ICOs' characteristics}

ICOs are an emerging topic in the literature but there is still a considerable literature gap due to their novelty (Chen \& Chen, 2020). ICOs' main function is to fund innovative ventures which are based on a distributed ledger technology (DLT) such as blockchain (Kher, Terjesen, \& Liu, 2020; Sharma \& Zhu, 2020). The funding is performed via the tokens selling by the cutting-edge technological ventures and the tokens purchase by worldwide investors (Chiu \& Greene, 2019). Therefore, the investors are able to buy tokens directly from the new venture without the need of a third party involved. The tokens sold will be venture capital project's functional future units, in other words, they will have a utility function, right of ownership or royalties (Fisch, 2019). According to Howell, Niessner, \& Yermack (2018) there are three main token categories: (i) currency token: used as a means of exchange and store such as a cryptocurrency; (ii) security token: used as a conventional security but recorded and exchanged on a blockchain. The underlying of this token type can range from corporate equity (typical share), to commodities, real estate or even currencies and; (iii) utility token: is the most common token type and provides to the buyer consumptive rights to access a product or service. According to Kranz et al., 2019 there is a fourth type of token, namely, the donation tokens which do not grant any rights to the investor and are used to raise money for entrepreneurial and idealistic projects. According to Brochado (2018b) there are also hybrid tokens which combine more than one of the characteristics mentioned above. Besides, new token types should appear in the future (Fisch, 2019). All the characteristics and main information on the ICO should be described in the Whitepaper of the new venture which, although unregulated, tries to mimic a regulated prospectus (Chiu \& Greene, 2019). According to Brochado (2018b) we could define ICOs as an alternative investment form that offers the possibility of direct financing 
from worldwide investors and which contributes to the democratization of entrepreneurship and access to capital markets. The ICOs are based on Blockchain technology and offer the chance to invest in a project's initial phase through the acquisition of a token. It also allows the transaction of tokens in the secondary market which is essential to their success (Chen Y. , 2018). This definition is in line with Fisch (2019) who also highlights the similar approaches of crowdfunding and ICOs, although an innovative characteristic of the latter is the possibility of selling tokens in a secondary market, which is not available in crowdfunding.

\subsection{ICOs' snapshot}

The ICO market represents large volumes of token sales but also large amounts of capital raised (Moedl, 2018). Data on ICOs cannot be completely correct and unbiased mainly due to two main reasons: (i) there are not official platforms where the ICOs might occur and be registered; (ii) several websites track ICOs but their data relies on manual user entries (Fisch, 2019). Nevertheless, the website CoinSchedule (www.coinschedule.com) is used by several authors and its information can be taken as reliable (Masiak, Block, Masiak, Neuenkirch, \& Pielen, 2018; Chiu \& Greene, 2019; Maume \& Fromberger, 2019; Rohr \& Wright, 2019).

The first ICO was the MasterCoin in 2013 proposed by J.R. Willett and since then the ICO market has increased mainly due to its novelty and the hype caused by the valorization of cryptocurrencies, particularly Bitcoin, between the years of 2017-2018 (OECD, 2019). During the last 4 years the ones with the largest amount of funds raised are 2017 and 2018. The year of 2017 had a total of 442 token sales concluded with USD 6.4 billion (thousand million) of funds raised and 2018 was even better for the ICO market with 1051 token sales concluded and with USD 21 billion (thousand million) of funds raised. However, with the depreciation of Bitcoin since the end-2018, the ICO market also refrained and 2019 registered lower values compared with previous years, namely, 131 token sales concluded and USD 1.4 billion (thousand million) of funds raised (Coinschedule, 2020). A global vision can be found in table 1.

Table 1 - Global vision of token sales and funds raised evolution

\begin{tabular}{|c|c|c|c|c|c|c|c|c|c|c|c|c|c|}
\hline \multirow{2}{*}{2016} & \multirow[t]{2}{*}{ Jan } & Feb & Mar & Apr & May & Jun & Jul & Aug & Sep & Oct & Nov & Dec & Total \\
\hline & & & & & & & & & & & & & \\
\hline Number of Token Sales Concluded & 1 & 0 & 1 & 0 & 5 & 1 & 4 & 4 & 6 & 7 & 10 & 13 & 52 \\
\hline Funds Raised & 300000 & - & 5500000 & - & 182719734 & 972798 & 2456342 & 12295227 & 11990546 & 12609349 & 22102411 & 5976334 & 256922741 \\
\hline \multicolumn{14}{|l|}{2017} \\
\hline Funds Raised & 82008737 & 22463657 & 18837264 & 81817029 & 289723458 & 662053515 & 492790512 & 426955503 & 868759649 & 979231108 & 813617738 & 1701690123 & 6439948293 \\
\hline \multicolumn{14}{|l|}{2018} \\
\hline Number of Token Sales Concluded & 97 & 109 & 110 & 120 & 141 & 97 & 89 & 64 & 55 & 60 & 64 & 45 & 1051 \\
\hline Funds Raised & 2098059389 & 1707584429 & 4486267223 & 1215465341 & 1973566501 & 5796394009 & 863487460 & 874328860 & 526327636 & 618923080 & 406763417 & 518758069 & 21085925414 \\
\hline Number of Token Sales Concluded & 24 & 19 & 21 & 9 & 7 & 12 & 9 & 4 & 9 & 5 & 9 & 3 & 131 \\
\hline Funds Raised & 290671532 & 111498733 & 193224902 & 73633660 & 91319322 & 158610707 & 57441868 & 11550000 & 373751392 & 43423497 & 46553123 & 2458940 & 1454137676 \\
\hline
\end{tabular}

Table 2 - Token sales by categories

\begin{tabular}{|c|c|}
\hline 2016 & \\
\hline Finance & $64,80 \%$ \\
\hline Blockchain Infrastructure & $14,40 \%$ \\
\hline Trading\&Investment & $4,70 \%$ \\
\hline \multicolumn{2}{|l|}{2017} \\
\hline Blockchain Infrastructure & $20,60 \%$ \\
\hline Finance & $16,90 \%$ \\
\hline Trading\&Investment & $12,40 \%$ \\
\hline \multicolumn{2}{|l|}{2018} \\
\hline Blockchain Infrastructure & $25,00 \%$ \\
\hline Finance & $15,40 \%$ \\
\hline Communications & $10,10 \%$ \\
\hline \multicolumn{2}{|l|}{2019} \\
\hline Trading\&Investment & $46,50 \%$ \\
\hline Payments & $8,80 \%$ \\
\hline Blockchain Infrastructure & $7,80 \%$ \\
\hline
\end{tabular}

The categories into which the ICOs fit have been changing since 2016. Nevertheless, the investment in blockchain infrastructure has been constant over time and is in the top three investments. In 2016 it represented $14.4 \%$ of the ICO investments, in 2017 it represented $20.6 \%$, in 2018 it represented $25 \%$ and in 2019 the total percentage investment in this category was $7.8 \%$. The investment in financial projects is also constant over 
time in the ICOs categories representing $64.8 \%$ of the investment in $2016,16.9 \%$ in 2017 and $15.4 \%$ in 2018 . Trading and investment platforms were in the top 3 investments in 2016 representing a percentage of $4.7 \%$, in 2017 representing $12.4 \%$ and in 2019 and $46.5 \%$ of the total investment. Two new categories appeared in the top three investments in 2018 and 2019. In 2018 ICOs in the communications category appeared with a total investment representing $10.1 \%$ of the total investment and the category payments represented $8.8 \%$ of the total investment in 2019 (Coinschedule, 2020). Furthermore, according to ICOBench (2020), which has a large database composed of 5690 ICO, the main ICO industries are: (i) platforms (3129 ICOs, USD 12.7B); (ii) cryptocurrency (2326 ICOs, USD 14.9B); (iii) business services (1271 ICOs, USD $4.3 \mathrm{~B}$ ); (iv) investment (996 ICOs, USD 3.4B), and; (v) smart contracts (840 ICOs, USD 2.1B). Geographically speaking, the counties with the largest number of ICOs are the following: (i) USA (716); (ii) Singapore (583); (iii) UK (505); (iv) Russia (328); (v) Estonia (299). In terms of the largest amount of funds raised in ICOs the top 5 countries are the following: (i) USA (\$7.3B); (ii) Singapore (2.5B); (iii) British virgin islands (2.4B); (iv) Switzerland (1.8B); (v) UK (1.5B) (ICOBench, 2020). A summary can be found in table 2 and figures 1 and 2.

The ICOs market represents significant amounts of investment despite the fact that in $201745 \%$ of them have failed (OECD, 2019). Furthermore, prior to trading in $2018,81 \%$ of the ICOs were considered as scams and only $8 \%$ moved to trade from which only $3.8 \%$ were successful (OECD, 2019). The fear of investing in a fraudulent project and the regulatory responses (Tiwari, Gepp and Kumar, 2020) have forced a decrease in the investment in ICO projects. However, recent literature has found that the previous percentages of scam projects are inflated. A study has found that, in the worst-case scenario, only $49 \%$ of sample used could be considered fraudulent projects. Projects' failure is more related with technical or entrepreneurial reasons rather than with a fraudulent activity. The same study develops a methodology useful for investors to identify fraudulent projects based on three criteria: (i) plagiarism; (ii) identity theft; (iii) advertising of improbably returns (Liebau \& Schueffel, 2019). A further study defends that it is a difficult task to predict fraud at the issuance time of a project. It also defends that the disclosure of information may not be a good predictor of the quality of a project due to plagiarism issues and because open-source codes, published in Github, may be the target of hackers jeopardizing the entire project (Hornuf, Kück, \& Schwienbacher, 2019). This argument supports the need for high quality signals in order to avoid information asymmetries between project's promoters and investors (Fisch, 2019). Furthermore, there is the need for third-party agents which could certify the quality of the project through specialized due diligence (Hornuf et al., 2019). The 5 ICOs which raised the largest amounts of funding represent a total of USD 7.8 billion. These ICOs are the following: (i) EOS (USD 4.1B): is a software based on blockchain technology creating a technology that has the potential to scale to millions of transactions per second, eliminates user fees and allows for quick and easy deployment of decentralized applications; (ii) Telegram Open Network (USD 1.7B): decentralized cryptocurrency which intends to be accessible to everyone (the founders state that bitcoin has established itself as the digital gold) integrating also a messenger service based on Telegram's blockchain; (iii) BITFINEX (USD 1B): is a cryptocurrency exchange allowing the buying and selling of several of these currencies; (iv) TaTaTu (USD $575 \mathrm{M}$ ): social platform with a reward system based on the attribution of tokens to be used in the platform's market; (v) Dragon (USD $320 \mathrm{M})$ : is a decentralized cryptocurrency to be used in casinos which use the company's blockchain facilities. Based on the information provided by ICOBench (2020), the authors have found that the team composition of the most successful projects are quite similar. The founding teams are considered commonly large as EOS project has 4 elements, Telegram has 5 elements, BITFINEX has 6 elements, TaTaTu has 12 elements and Dragon has 17 elements. These teams are quite diversified as ICO projects use global talent as its source. The founding members are from different regions of the world. The teams have elements with managerial and technological experiences and sometimes both combined. There is a predominance of members with university degrees, mainly bachelor and master degrees. The ratings attributed by external parties to the project are considered high as the lowest rating of 3.2 was attributed to the Dragon project and the highest rating of 4.1 was attributed to EOS project. The team ratings are considered very high (except for the Dragon project which was unavailable) as the lowest rating was 3.6 attributed to TaTaTu and the highest of 4.8 to BITFINEX.

The huge attention given to ICOs is also verified by a Google trends analysis. The ICO topic had a peak in popularity in the years of $2017-2018$ and the level of interest reached 100 points between those years as per figure 3 (Google, 2020). The high level of interest verified is also in line with the amounts of funds raised as explored before.

One of the reasons that explain the increasing amount of funds raised in ICOs during the years of 2017-2018 is the increase of value of cryptocurrencies during those years (Fisch, 2019; OECD, 2019) because shocks in cryptocurrencies have impacts on ICO volumes (Masiak et al., 2018). Not only the interest in these kinds of topics raises awareness of a wider public but also a constant increase of value of cryptocurrencies that are used to finance ICOs contributes to a larger amount of funds the new ventures can obtain. The authors have collected data on the funds raised by ICOs from Coinschedule (2020) and data on Bitcoin and Altcoins' market capitalization from CoinDance (2020) (previously used in research by Sovbetov (2018)) and performed a simple linear regression between both. Therefore, a correlation was found with an R-squared of 0.2 with data between the years of 2016-2019 as per figure 4. The movements can be easily observed in the line chart in figure 5 . Altcoins have been introduced recently as feasible alternatives to Bitcoin and their introduction has a negative effect on Bticoin's returns (Nguyen, Nguyen, Nguyen, \& Nguyen, 2019). The correlation between ICOs funds raised and cryptocurrencies market cap is even larger when only Altcoins are considered.

\subsection{Advantages and disadvantages of ICOs}

The ICOs are a new and innovative way of funding projects which have several advantages from which investors can take advantage. According to Brochado (2018b) the advantages can be distinguished between entrepreneurs and investors. The main advantages to the entrepreneurs begin

Page $4 / 21$ 
with the fact that many projects are open source (e.g. Wikipedia) and that the ICO is a way of rewarding the promoters of these projects. Through the ICOs the entrepreneurs can have access to a large number of investors globally and this constitutes a form of financial investments democratization. The promoters' network is crucial for a successful campaign and the appreciation of a token's value can increase the investment on it due to the awareness created which also leads to a wide brand exposure. The utility tokens work as a sign of demand for the product offered and can help entrepreneurs take decisions. For the investors, the ICOs offer the possibility of a wider portfolio diversification not only due to being a different type of investment but also due to a large spectrum of projects in several industries (Adhami \& Guegan, 2019). This global reach of ICOs is also important for investors who can invest worldwide. Besides, there is a democratization of investments also for investors once there are much lower costs associated with ICOs investment and also a lower entrance amount. The investors can enter in the project in its very initial phase being the tokens bought as a liquid asset exchanged in several platforms. Although not guaranteed, the existence of a secondary market for tokens (listed on crypto-exchanges) is desirable and highly recommended to the promoters of the ICOs once it gives the possibility to the investors to trade their tokens (Boreiko, Ferrarini, \& Giudici, 2019) and also provides a view of the projects' success once the token's price is in principle determined freely (OECD, 2019). Crypto exchanges are gaining huge importance which are seen as complementary to the ones in capital markets (Boreiko et al., 2019). There are also some disadvantages in the use of ICOs for entrepreneurs and investors. The entrepreneurs can face an opportunity cost due to selling the tokens in an early phase when the tokens are still undervalued and also face serious difficulties achieving the financing needed. This difficulty is particularly present in hard cap projects once this imposition means that an amount which should be raised is previously established and translated into a cap in the number of tokens that will be raised. The projects without a hard cap may suffer from the erosion of the value of the token since new tokens are constantly issued and force depreciation of previous ones (OECD, 2019). Investors who finance a project in such an early stage admit a high risk once they are investing in project that is still intangible and that may have little information on them which leads to a deficient project's evaluation. As a high percentage of ICOs are confirmed as scams, investors may finance fraudulent projects. Cybersecurity is also an issue due to possible breaches in personal accounts. Furthermore, although a secondary market for ICOs should exist it does not imply low token volatility. A disadvantage to both entrepreneurs and investors is a possible tough fiscal policy on money obtained through an ICO. On the other side, a risk posed to regulators is fiscal evasion or money laundering through these investments since they are mostly anonymized and thus criminals can take advantage of technology to pursue criminal activities (Foley, Karlsen, \& Putniņš, 2018). Nevertheless, evidence based on ICO statements issued by regulators shows that they do not seem to focus on utilization by criminals of these instruments, which do not constitute high risk, but mostly with fraud (Dostov, Shust, Leonova, \& Krivoruchko, 2019). In general terms, the risks associated with fintechs may also be applied to the use of ICOs and therefore divided in risks for the consumers, companies and financial stability (KPMG, 2019). Consequently, the main risks for consumers are associated with the lack of consumer understanding and deficient selling of products and services. Concerns are also raised in terms of data privacy, security and protection as well financial exclusion of populations due to less access to technology (Meena, Sriram, \& Sundaram, 2017; Chen Y. , 2018). However, the use of digital financial services promotes inclusion and entrepreneurship even for populations living in less developed countries with less access to technology (Larios-Hernández, 2017). Companies using these innovative solutions (i.e. fintech or ICOs) will also need to assess their business model viability such as conducting a strong AntiMoney Laundering (AML) policy. They will also need to be able to handle high amounts of data. If ICOs become widely used, they may also pose challenges to the entire financial stability such as concentration, wide use of crypto assets, the use of alternative challenges of financial intermediation and herd-like behavior (OECD, 2019).

\subsection{ICOs' Investment Process and Ecosystem}

The process of investing in an ICO starts by identifying the ongoing opportunities and also by collecting information on more interesting projects. Then, the investor should select an exchange and open an account to which fiat currency should be transferred and used to acquire virtual currencies. At that point, the investor should select a wallet. The process's last phase is to check the ICO's Agreement (i.e. Whitepaper), download the recommended wallet and buy tokens transferring the virtual currency previously purchased to the ICO address. The tokens should be kept or sold in an Exchange (Kranz et al., 2019). The main aspects of the project are described on the so-called Whitepaper which has not only the detailed aspects of the project but also its expected returns from dividends or participation on the company's capital. Most ICOs are capped and happen in Ethereum blockchain (Howell et al., 2018).

The ICOs' ecosystem is composed of several players being individuals or institutions willing to invest or be financed (Spinedi, Rigotti, Canetta, Camoesa, \& Redaelli, 2019). Among others, the players are digital exchanges, trading platforms, digital wallet providers, financial and technological advisors and traditional players if ICOs are used in traditional financial market schemes, for instance, bought by hedge funds. The networks are of extreme importance in ICOs hand in hand as marketing and information spread about the project. Information might be shared in social media or specialized websites. The network importance is proved by the "airdrop" technique in which promoters deliver free tokens to active wallets in order to create awareness of the projects and attract more investment (OECD, 2019). Token sales are usually characterized by four main aspects: (i) cap on the amount of money to raise: uncapped ICOs cause issues with price volatility; (ii) time limit for the token sale: although currently ICOs receive most investments within the first moments of the sale the process closes as soon as the time established expires or the cap limit is reached; (iii) transparency of the total number of tokens in circulation and in the sale: crucial for buyers in order to determine the tokens' value during the token sale; (iv) clear token value: token value can be explicitly stated or easily derived from the cap limit and number of tokens available (Massey, Dalal, \& Dakshinamoorthy, 2017). Currently, besides the ICO model there are also two additional models, namely, Initial Exchange Offering (IEO) and Security Token Offering (STO). IEOs are popular since 2019 and contrary to the ICOs they happen in a specific crypto exchange and are conducted

Page 5/21 
by a determined platform which charges fees and a percentage of tokens to the new venture. STOs are security tokens issued publicly traded and with some degree of regulation and investor protection in some jurisdictions. STOs, contrary to ICOs, offer some rights to the buyers and are backed by companies' assets (Davis, et al., 2019).

\subsection{Lifecycle of an ICO}

According to Kranz et al., (2019) the token sales, commonly referred here as ICO, have three main stages which can be considered the project's lifecycle and have specific characteristics and activities. These phases are: 1) pre-token sale; 2) token sale; 3) post-token sale.

In the first and longer stage of the process, named by the authors the "pre-token sale", the promoters should decide on the type of tokens to be sold among the several possibilities (donation, utility, currency or security tokens) according to the project's characteristics and investors' expectations. Thereafter, the promoters should decide on whether to apply caps and their typology, in other words, the maximum limit of tokens issued and their value. The type of caps are: (i) no cap: where there are no limits for the issue of new tokens and capital raised which has negative impacts on the value of tokens (OECD, 2019) ; (ii) soft-cap: defines a minimum amount of tokens to be sold and the investment will be returned if this limit is not achieved; (iii) hard-cap: an upper limit of tokens to sell is defined and once reached no more investment is accepted; (iv) collect and return: a hardcap is defined and if surpassed the tokens will be distributed respecting the ratio of the hard cap to the total funds received; ( $v$ ) dynamic ceiling: several hard-cap limits are defined and kept secret. Therefore, the token sales will be done in several rounds avoiding the dominance of a small group of big investors. The promoters should also define the tokens' pricing model which can be fixed or floating and define the token sales' schedule which can include a pre-sale where tokens are sold at a discount and this is used to attract visibility and investment. After the designs are defined a smart contract must be developed. The final task of this stage is to publish the Whitepaper with all the relevant information on the project which should be as detailed as possible to overcome the lack of regulation (Howell, Niessner, \& Yermack, 2018).

The second phase is named the "token sales" and starts with the activation of the smart contract and the actual sale of tokens which usually lasts for 41 days (Benedetti \& Kostovetsky, 2021). During this phase a due diligence on the investors might be requested in order to avoid money laundering activities. The actual token sales happen when the investors' funds are transferred to the promoters' wallets via the smart contract.

The third and last phase according to Kranz et al., (2019) is the "post-token sales" in which the tokens are distributed to the investors' wallets via the smart contract. The issuers should then develop the product or service financed and keep the relation with investors healthy by keeping them informed and engaged in order to increase awareness and recognition on the project since it most likely is listed in a crypto exchange subject to price volatility as traditional stocks.

\section{Human Capital In Ico Project}

\subsection{Human Capital Theory (HCT) and the ICO projects}

The Human Capital Theory (HCT) is focused on the individual and states that the individuals and the society strongly and consistently benefit from the investment in people. This theory also differentiates the consumptive expenditures from the human capital expenditures since the first provides fewer and immediate benefits while the second is considered an investment (Sweetland, 1996). This theory has its firsts roots in the eighteenth century with economists such as Adam Smith, John Stuart Mill and Alfred Marshall who focused on the fact that labor inputs must not only be considered quantitative but also qualitative, since workers acquire abilities which increase productivity (Sweetland, 1996). Further studies have been developed to focus particularly on education and experience proving that better educated people are also better paid (Mincer, 1958; Schultz, 1961) and more productive (Fabricant, 1959). Moreover, studies have been developed on the subject mainly due to the interest raised in the USA aiming to explain a large part of economic growth unaccounted by conventional economic means (Becker, 1994). Several studies have focused on the human capital characteristics without mentioning their direct link to HCT. Nevertheless, more recent research has evolved to include further human capital characteristics and link them to the success obtained by ventures and companies with a direct link to the theory (Bruderl, Preisendorfer, \& Ziegler, 1992). Studies focused on the HCT have argued that human capital characteristics influence organizational success since greater human capital increases the productivity of the founder, who is able to better use his or her inputs, which then increases company's profits (Bates, 1985). Indeed, human capital is positively related to better planning and strategy which influences success (Unger, Rauch, Frese, \& Rosenbusch, 2011). There are also mechanisms which operate prior to the founding of the enterprise since better human capital equipped individuals obtain higher previous income which allows them to set larger businesses with higher financial stability (Bruderl et al., 1992). Human capital is found to be also important to overcome eventual lack of financial capital (Brush, Greene, \& Hart, 2001) . Furthermore, human capital is seen as important to endow founders with the capabilities of foreseeing and exploring market opportunities which contributes to the success of a project (Unger et al., 2011). Human capital signals are important to reduce information asymmetries between investors and promoters which should lead to a better perception of the venture (Piva \& Rossi-Lamastra, 2018). The human capital characteristics are particularly decisive in younger businesses (Unger et al., 2011).

Overall, the human capital characteristics are considered to be linked with the success of a company and the individual success. Characteristics such as years of schooling and work experience are seen as important success factors (Bruderl et al., 1992). Further characteristics such as 
business education, entrepreneurial experience and networks (Linkedln connections) are also considered to be important human capital characteristics (Piva \& Rossi-Lamastra, 2018). Nevertheless, studies based on human capital theory frequently assume that experience means knowledge and skills (Frese \& Rauch, 2001). This is not always the case as more experience may not mean that an individual is a better professional. This differentiation is sharper when analyzing the tasks performed by excellent and average professionals (Sonnentag, 1995).

\subsection{ICOs' corporate governance and human capital}

ICOs have been compared with crowdfunding, Venture Capital (VC) and Initial Public Offerings (IPOs) (Block, Groh, Hornuf, Vanacker, \& Vismara, 2020), which are traditional ways of project financing, but there are substantial differences between these concepts (Biasi \& Chakravorti, 2019) and ICOs have also been challenging them (Schückes \& Gutmann, 2020). Besides some common characteristics between the concepts they are mostly distinct and, consequently, so is the relationship between entrepreneurs and investors (OECD, 2019). The main difference in the entrepreneurinvestor relation among the different financing forms is the complete inexistence of intermediaries in pure ICOs (OECD, 2019). The same does not happen in crowdfunding (Delivorias, 2017), VC (Gompers \& Lerner, 2001) or IPOs (Howell, Niessner, \& Yermack, 2018). The regulation is very tight in IPO processes where a rigid due diligence is made on the company and on the investors, which creates barriers to participate in the process (Khurshed, 2019), while ICOs are mainly unregulated (Zhang, Zhang, Zheng, \& Aerts, 2020). Investors will ultimately interact with each other and indirectly with the entrepreneurial team when the token is traded in the secondary market available in ICOs but not in crowdfunding (Brochado, 2018 b) or VC (OECD, 2019).

As stated before, ICOs have two main measures of fundraising goals: (i) soft-cap, and; (ii) hard-cap. Therefore, the total amount raised by an ICO is considered to be the best measure of its success (An et al., 2019; Fisch, 2019). Although founders' collective human capital affects the amounts raised by an ICO (An et al., 2019) most of them are not subject to traditional corporate governance rules since entrepreneurs and promoters have total control over the funds raised which increase the need to a strong corporate governance (Goergen \& Rondi, 2019; Momtaz, 2020). Hence, most ICOs do not have a formal or informal type of board which works as an oversight mechanism of management. Besides, regular reporting is not a frequent practice which poses a further risk to investors (OECD, 2019). Therefore, if a traditional company wishes to pursue an ICO, it should also have several impacts on its current corporate governance. These facts increase the importance of a strong entrepreneurial team in order to achieve the success expected (Spinedi et al., 2019). VC companies state that the most important feature of a new project is the experience of the team. Skills are considered the most frequent selection criteria for VC companies. Besides, projects with larger top management teams, presidents with wider roles and that currently preside other projects, obtained much higher VC funding. The fact that the president executes several roles proves that he has more expertise but, on the contrary, if the president has participated previously in entrepreneurial projects with less success that negatively affects the funding of the current one (Baum \& Silverman, 2004).

The human capital characteristics of the founding team can be considered the following: (i) professional experience (Giudici \& Adhami, 2019); (ii) experience in blockchain projects (Brochado, 2018b); (iii) entrepreneurial profile (Howell, Niessner, \& Yermack, 2018); (iv) number of founders (Jin, et al., 2017); (v) existence of social media accounts (Albrecht, Lutz, \& Neumann, 2019; Yeh \& Chen, 2020). Investors prefer teams with founders who have a past record of success in blockchain projects (Brochado, 2018b). According to a study performed using a database of 935 ICOs between 2014-2017, the probability of success is positively related with the number of members in the project team and the number of members of the advisory committee as well as to the token retention rate by the ICO promoters (Giudici \& Adhami, 2019). The importance given to the size of the teams is particularly important for new ventures, which face complex tasks and uncertain environments, since it is viewed as a way of exchanging information (Jin, et al., 2017). The diversity associated with team size is considered important to improve the decision quality and organizational performance (Boone \& Hendriks, 2009). New ventures have better changes of survival if their teams are considered to have a high degree of diversity (Zimmerman \& Zeitz, 2002). Larger teams also have the chance to combine skills leading to better performance, but larger team size could also mean inefficiency due to the existence of too much expertise and management styles (Lechler, 2001). Cohesion of the founding team is considered important in order to maintain the stability of the team since instability may lead to members' exit. Indeed, larger founding teams are negatively correlated with later members' entry and positively associated with members' exit (Ucbasaran, Lockett, Wright, \& Westhead, 2003). Therefore, we have found arguments in favor of larger teams with warnings concerning their failure leading us to conclude that both small and large teams have their own advantages. Other human capital variables are not that relevant for ICOs' success such as education or teams with more entrepreneurial experience (Giudici \& Adhami, 2019). The same logic is already applied to crowdfunding once one of the sources of credibility is the entrepreneurs' human capital which is characterized by education and experience. Thus, both education and experience are positively correlated with a good crowdfunding performance but only the second is statistically relevant (Allison et al., 2017). On the opposite, in entrepreneurship, the entrepreneurs' education and experience is important for external stakeholders. It is also perceived that entrepreneurs with high academic degrees tend to pursue innovative strategies but entrepreneurs with experience in finance or sales do not (Burton, Sørensen, \& Beckman, 2002). Finally, the disclosure of teams' information is linked to higher funds raised. In terms of time needed to successfully complete an ICO, there is also a positive relation between less time needed to achieve ICO's goals and the existence of a founding team with business, blockchain and technology experience, corporate board background and large social networks (An et al., 2019).

\subsection{Model and hypothesis}


Building on the human capital theory, the characteristics of the entrepreneurs influence the outcome of their projects. Indeed, studies suggest that education improves economic capabilities of people (Schultz, 1961) and positively impacts the outcome of a project side by side with other variables such as professional experience and geographic location (Bruderl et al., 1992). Current literature has also focused on the human capital characteristics in crowdfunding (Piva \& Rossi-Lamastra, 2018) and entrepreneurship suggesting that human capital variables are important for a successful project (Unger et al., 2011). Literature dedicated to the study of ICOs has also dedicated attention to the founders' characteristics and their impact on the outcome of a project (An et al., 2019; Giudici \& Adhami, 2019). Hence, we have built our research on the human capital theory and the characteristics identified as having an impact on the success of a project. Therefore, our research aims to test the hypothesis that team's characteristics influence the success of ICOs projects (Fisch, 2019). We have tested this hypothesis following a quantitative approach. We have developed three econometric models with three different dependent variables following the approach by Jong et al., (2018).

\section{Methodology}

\subsection{Database and variables}

The data used in this research is secondary and collected from ICOBench a website which comprises a large database on ICOs (ICOBench, 2020). The information provided by the website is mostly related to the projects and concerns among other data: the project's year, amounts raised, type of cap, existence of pre-sales or bonus schemes. It also compiles information on the team, such as their composition and functions. The data was collected via a premium subscription which gave access to an API. As the main objective of the research is to study the ICO's teams, the complementary information was collected from the public Linkedln profiles of the team members. This resulted in the collection of 556 ICO projects, on the banking/financial area, from which 216 were discarded due to lack of crucial information and leaving the database with 340 projects. The projects' teams were composed of 5025 profiles from which we were able to keep 3158 once 1867 were discarded due to lack of crucial information. We have selected ICO projects in the banking/financial area due to the impact this industry faces and the challenges put to their traditional business model with the appearance of fintech companies. Financial institutions' role as third parties is being challenged by new models such as ICOs (Campino, Brochado, \& Rosa, 2020). Furthermore, the industry in which the project is developed influences its outcome (Hartmann, Grottolo, Wang, \& Lunesu, 2019) since some industries have tendentially less successful projects (Davies \& Giovannetti, 2018). We would like to avoid the risk of a biased result given the specificities of our research focused on the human capital. There are some studies using a mixed industry database (An et al., 2019) and thus, we would like to differentiate from that approach in this case.

There is no consensus concerning the most correct measure for ICOs' success and thus we have developed three of them and tested them in different models (Jong et al., 2018). The first dependent variable is a binary variable of achievement of the minimum level of capital defined by the project's promoters. The second dependent variable is the natural logarithm of the percentage above the minimum capital achieved, in other words, the successful projects are the ones which achieve at least the minimum capital and the most successful will be the ones which surpass that threshold by a higher percentage. The last dependent variable is the natural logarithm of the total capital achieved. We have defined several independent variables concerning the team: (i) person location; (ii) number of projects per person; (iii) number of Linkedln connections; (iv) previous managerial experience; (v) previous technology experience; (vi) education; (vii) business degree; (viii) technology degree; (ix) team rating; (x) vision rating; (xi) number of team elements. The control variables included and related with the project itself are: (i) soft cap limit existence; (ii) hard cap limit existence; (iii) token price; (iv) currencies accepted in the ICO; (v) the ICO is based on an Ethereum platform; (vi) bonus scheme existence; (vii) ICO rating according to ICOBench; (viii) ICO year. We have summarized the variables in table 3.

Table 3 - Variables included in the econometric models

\begin{tabular}{|c|c|c|c|}
\hline Variable & Description & Coding & Source \\
\hline \multicolumn{4}{|l|}{ Dependent Variables } \\
\hline Log of capital raised & Logarithm of the total capital raised in USD & Decimal & ICO Bench \\
\hline Log of capital raised over soft-cap & Logarithm of the total capital raised divided by the soft-cap threshold in USD & Decimal & ICO Bench \\
\hline Soft-cap achleved & Binary variable of soft-cap threshold achievement & Binary & $1 \mathrm{CO}$ Bench \\
\hline \multicolumn{4}{|l|}{ Independent Variables } \\
\hline Bonus scheme & Binary variable of bonus scheme existence & Binary & $1 \mathrm{CO}$ Bench \\
\hline Business Degree & Binary variable of profile's education & Binary & Linkedin \\
\hline Currencies Accepted & Number of currencles accepted by the project & Integer & ICO Bench \\
\hline Education & Level of education acheived & Integer & Uinkedin \\
\hline Ethereum Platform & Binary variable identilying if the project is based on Ethereum & Binary & ICO Bench \\
\hline Fundralsing Goal & Binary variable identilying the existence of a fundraising goal such as had-or soft-cap & Binary & ICO Bench \\
\hline ICOYear & Year of the ICO campaign & Integer & ICO Bench \\
\hline Linkedin Connections & Connections on Linkedin & Integer & Linkedin \\
\hline Managerial Experience & Binary variable of profile's experience & Binary & Unkedin \\
\hline Number of projects per person & Number of projects in which each person participated & Integer & ICO Bench \\
\hline Number of team elements & Size of project'steam & Integer & ICO Bench \\
\hline Location & Location of the team member. Sub-divided into regions, e.g. America and Europe. & Binary & Unkedin \\
\hline ICO Rating & Rating attributed by ICO Bench & Decimal & ICO Bench \\
\hline Team Rating & Rating attributed by $\mathrm{ICO}$ Bench & Decimal & ICO Bench \\
\hline Technology degree & Binary variable of profile's education & Binary & Linkedin \\
\hline Technology Experlence & Binary variable of proflle's experience & Binary & Uinkedin \\
\hline Token Price & Price of the token when lauched & Decimal & ICO Bench \\
\hline Vislon Rating & Rating attributed by ICO Bench & Decimal & $1 \mathrm{CO}$ Bench \\
\hline
\end{tabular}

\subsection{Robust regression and multiple logistic regression}


In order to regress our model, test the assumptions and perform several graphs we used the software STATA 14 . We started by performing a matrix scatter plot for all the variables in our model and have confirmed that sometimes the data appeared to have a normal distribution but most of the times that was not the case. The non-normality of the residuals is confirmed when a skewness and kurtosis test is performed which confirmed the null hypothesis. Furthermore, we have performed a Shapiro-Wilk test which confirmed that the residuals were not normally distributed (STATA, 2020a). The data also suffered from heteroskedasticity once the residuals exhibit non-constant variation confirmed by the Breusch-Pagan test and reinforced by the White's general test for heteroskedasticity which overcomes some limitation of the first test (Williams, 2020). We have also checked for multicollinearity performing a Variance Inflation Factor (VIF) test which did not confirm collinearity. Therefore, regressing the model using the OLS method for the logarithmic variables could lead to biased estimations and we adopted the robust regression using the command "rreg" in STATA (STATA, 2020b) which is a strong substitute to the standard OLS method since it offers protection against distortion of anomalous data ( $\mathrm{Li}, 1985)$. Concerning the binary variable measuring the achievement of the soft-cap threshold a different model was used, namely, the multiple logistic regression model using the command "logit" in STATA (STATA, 2020c).

\section{Results}

\subsection{Profiles descriptive statistics}

The focus of our research is the ICO promoters' profiles and thus we have developed several descriptive statistics on the profile's characteristics. Regarding networks which are crucial in this type of projects, we verified that the profiles analyzed have large networks judging by the Linkedln connections. In our sample, $71 \%$ of the profiles have 500 or more connections on Linkedln and $97 \%$ have 1 social network. The most used social network is LinkedIn (source of several information on the profiles) followed by Facebook and Twitter.

The large majority of the profiles are located in Europe (49\%) followed by Asia-Pacific (25\%), North America (17\%) and other regions (9\%). Within Europe the predominant countries are the UK (18\%), Russia (15\%), France (8\%), Switzerland (7\%), Germany (5\%) and Ukraine (5\%). In North America the United States are by far the country with more promoters with $88 \%$ of the sample and Canada representing $12 \%$. In the Asia-Pacific region the predominant countries are India (21\%), Singapore (18\%), Australia (10\%), Korea ( $8 \%$ ) and China (5\%). The remaining regions represented in the sample are the Middle East (38\%), Africa (29\%), South America (27\%) and Central America (6\%).

The profiles on our sample are highly educated since $98 \%$ have an academic degree. From the entire sample $52 \%$ have a bachelor degree, $40 \%$ have a Master degree, $6 \%$ have a PhD and therefore only $2 \%$ have no academic degree. The percentage of profiles with a business or technology degree is roughly the same with $35 \%$ and profiles having both degrees represent $8 \%$ of the sample.

Regarding previous professional experience we concluded that $69 \%$ of the profiles had a managerial experience and $25 \%$ had a technology experience. Profiles combining both experiences represent $11 \%$ of the sample. In terms of project participation, $96 \%$ of the profiles participated in 1 project, $3 \%$ in 2 projects and 1\% in more than 2 projects. The teams are composed by $18 \%$ of advisors. Within the ICO teams (excluding advisors) $51 \%$ have managerial functions, $32 \%$ have a technological function and $11 \%$ have both functions. The main functions' titles are in line with traditional companies but these projects include innovative positions, for instance, in the board. The main functions titles are represented in figure 6.

\subsection{Variables descriptive statistics}

We have developed a correspondence table which allows a deeper understanding of the distribution of variables conditional to the dependent variable selected.

Table 4 - Cross-table between dependent and independent variables 


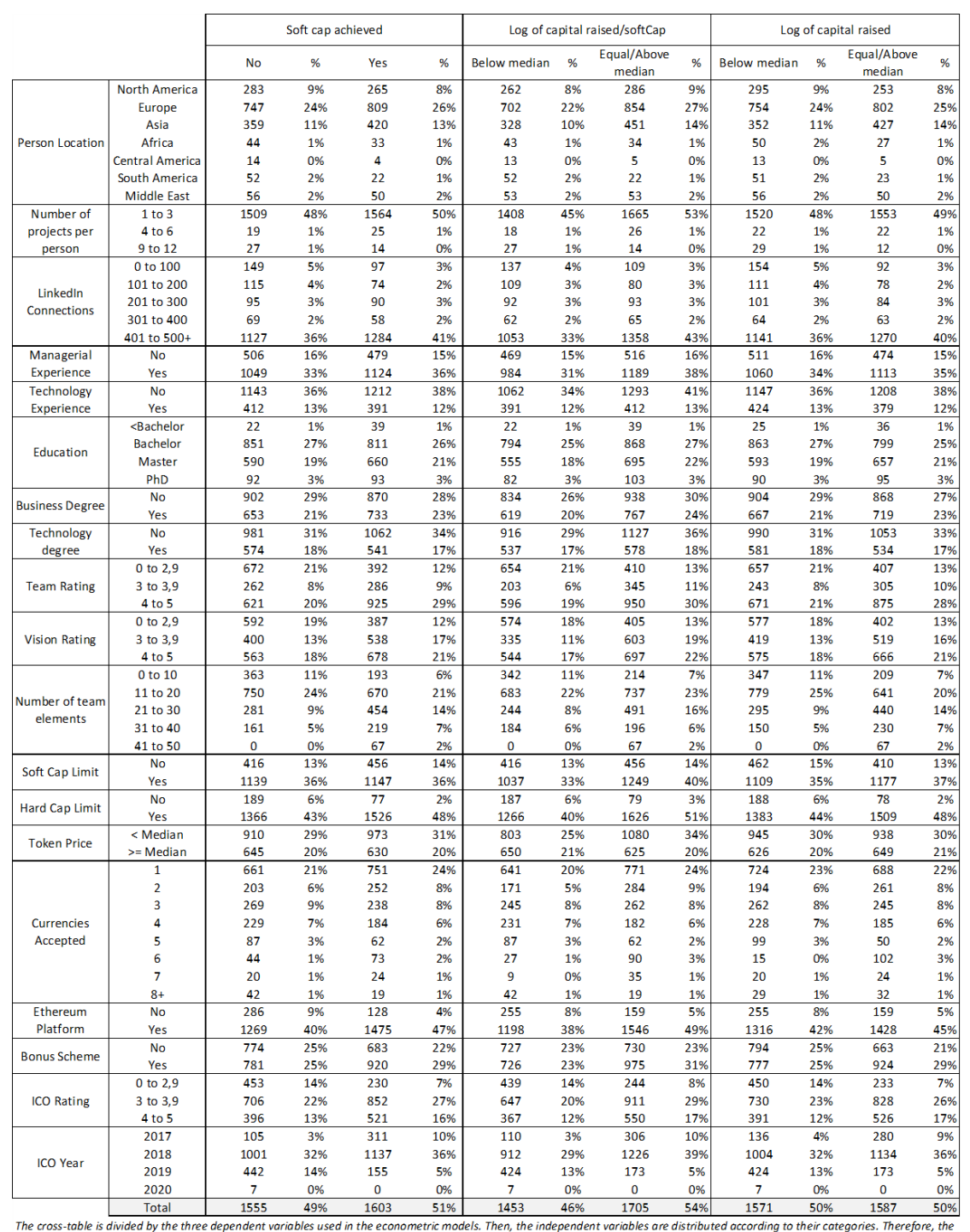

The cross-table is divided by the three dependent variables used in the econometric models. Then, the independent variables are distributed according to their categories. Therefore, the
table allows a comprehensive view on the distribution of variables into successful and unsuccesfful projects. The results are similar regardless of the dependent variable used.

Table 4 identifies all the independent variables used in the econometric model and depicts their distribution given the dependent variable selected. For instance, it depicts the geographic profiles' distribution linking it to a successful or unsuccessful project. Therefore, we conclude that the variable distribution is similar regardless of the dependent variable selected. In terms of geographic location there is a trend of more successful projects promoted by profiles located in Europe and Asia-Pacific. The North American region is associated with similar percentages of success and unsuccess regardless of the measure selected. The remaining regions tend to have more unsuccessful projects except for the Middle East which, as North America, tends to have the same percentages for successful and unsuccessful projects. As the large majority of the profiles participate in 1 up to 3 projects, the most successful ones are within this range and when the project's participation increases, they are less successful. As previously stated, the networks are crucial in this type of projects and thus having a higher number of connections on Linkedln is also associated with more successful projects. In the correspondence table we confirm that profiles with less connections tend to be associated with less successful projects and the contrary happens with profiles with higher number of connections. In terms of professional experience, we confirm that although the difference is small, there is a higher percentage of successful projects when the profile had previous managerial experience and the contrary happens when the profile has previously technological experience. The variable education, which is divided into several levels, does not have a significant variation in percentage of successful projects when the level of education increases. For instance, the PhD level has always the same percentage of successful and unsuccessful projects and the highest difference in the percentages is using the dependent variable log of capital raised over soft-cap threshold and for bachelor and master's levels where there is a higher percentage of successful projects. Regarding the type of academic degree, we can see that the same situation happens with the professional experience once although small percentage differences, there is a tendency to have successful projects when the profile has a business degree inversely to when the profile has a technology degree. The projects' ratings are attributed by a combination of an automated analysis from the ICOBench's algorithm together with experts' evaluation (ICOBench, 2020). Therefore, they are an important factor to be considered by the investors before deciding to whether to support a project or not. As expected, the variable team rating shows considerable percentage changes between successful and unsuccessful projects depending on the attributed rating. The teams with lower ratings are associated with less successful projects. Together with the team rating, the vision rating also shows the same trend although much more moderated. Across all the dependent variables the tendency to have successful projects linked to larger teams is verified. The teams with less people tend to be less successful than projects with larger teams. 
In table 5 we also present the descriptive statistics for each variable including their mean, standard deviation, minimum and maximum values. For the nominal and ordinal variables, we present the frequencies table in table 6.

As previously mentioned, the data did not suffer from collinearity issues as confirmed by the VIF test performed. As per the correlation and VIFs analysis performed[1], we confirmed that VIF values are low for every variable and there is no further need to take corrective measures. The values are always below 5 with a mean of 1.67 .

Table 5 - Descriptive statistics

\begin{tabular}{cccccc} 
& \multicolumn{5}{c}{ Descriptive Statistics } \\
\cline { 2 - 6 } Number of Projects per Person & Observations & S.D. & Min. & Max. & Mean \\
\cline { 2 - 6 } & 3158 & 1.21 & 1 & 12 & 1.27 \\
Number of Team Elements & 3158 & 9.25 & 1 & 47 & 18.93 \\
Token Price & 3158 & 179.90 & 0 & 3000 & 20.07 \\
Currencies Accepted & 3158 & 2.49 & 1 & 30 & 2.56 \\
\hline
\end{tabular}

The descriptive statistic table displays key statistics for the variables, namely, number of observations, standard deviation, minimum and maximum values and the mean.

Table 6 - Frequencies table

\begin{tabular}{|c|c|c|c|c|}
\hline & \multirow[b]{3}{*}{ North America } & \multicolumn{3}{|c|}{ Frequencies Table } \\
\hline & & Frequency & Percentage & Cumulative Percentage \\
\hline \multirow{8}{*}{ Location } & & 548 & $17 \%$ & $17 \%$ \\
\hline & Europe & 1556 & $49 \%$ & $67 \%$ \\
\hline & Asia & 779 & $25 \%$ & $91 \%$ \\
\hline & Africa & 77 & $2 \%$ & $94 \%$ \\
\hline & Central America & 18 & $1 \%$ & $94 \%$ \\
\hline & South America & 74 & $2 \%$ & $97 \%$ \\
\hline & Middle East & 106 & $3 \%$ & $100 \%$ \\
\hline & Total & 3158 & $100 \%$ & - \\
\hline \multirow{4}{*}{ Linkedln Connections } & $<=200$ & 435 & $14 \%$ & $14 \%$ \\
\hline & 201 to 400 & 312 & $10 \%$ & $24 \%$ \\
\hline & $>=401$ & 2411 & $76 \%$ & $100 \%$ \\
\hline & Total & 3158 & $100 \%$ & - \\
\hline \multirow{3}{*}{ Managerial Experience } & No & 985 & $31 \%$ & $31 \%$ \\
\hline & Yes & 2173 & $69 \%$ & $100 \%$ \\
\hline & Total & 3158 & $100 \%$ & - \\
\hline \multirow{3}{*}{ Technological Experience } & No & 2355 & $75 \%$ & $75 \%$ \\
\hline & Yes & 803 & $25 \%$ & $100 \%$ \\
\hline & Total & 3158 & $100 \%$ & - \\
\hline \multirow{5}{*}{ School Degree } & $<$ Bachelor & 61 & $2 \%$ & $2 \%$ \\
\hline & Bachelor & 1662 & $53 \%$ & $55 \%$ \\
\hline & Master & 1250 & $40 \%$ & $94 \%$ \\
\hline & $\mathrm{PhD}$ & 185 & $6 \%$ & $100 \%$ \\
\hline & Total & 3158 & $100 \%$ & - \\
\hline \multirow{3}{*}{ Business Degree } & No & 1772 & $56 \%$ & $56 \%$ \\
\hline & Yes & 1386 & $44 \%$ & $100 \%$ \\
\hline & Total & 3158 & $100 \%$ & - \\
\hline \multirow{3}{*}{ Technological Degree } & No & 2043 & $65 \%$ & $65 \%$ \\
\hline & Yes & 1115 & $35 \%$ & $100 \%$ \\
\hline & Total & 3158 & $100 \%$ & - \\
\hline \multirow{4}{*}{ Team Rating } & $0-2,9$ & 1064 & $34 \%$ & $34 \%$ \\
\hline & $3-3,9$ & 548 & $17 \%$ & $51 \%$ \\
\hline & 4.5 & 1546 & $49 \%$ & $100 \%$ \\
\hline & Total & 3158 & $100 \%$ & - \\
\hline \multirow{4}{*}{ Vision Rating } & $0-2,9$ & 979 & $31 \%$ & $31 \%$ \\
\hline & $3-3,9$ & 938 & $30 \%$ & $61 \%$ \\
\hline & $4-5$ & 1241 & $39 \%$ & $100 \%$ \\
\hline & Total & 3158 & $100 \%$ & - \\
\hline \multirow{3}{*}{ Soft-cap Limit } & No & 872 & $28 \%$ & $28 \%$ \\
\hline & Yes & 2286 & $72 \%$ & $100 \%$ \\
\hline & Total & 3158 & $100 \%$ & - \\
\hline \multirow{3}{*}{ Hard-cap Limit } & No & 266 & $8 \%$ & $8 \%$ \\
\hline & Yes & 2892 & $92 \%$ & $100 \%$ \\
\hline & Total & 3158 & $100 \%$ & - \\
\hline \multirow{3}{*}{ Ethereum Platform } & No & 414 & $13 \%$ & $13 \%$ \\
\hline & Yes & 2744 & $87 \%$ & $100 \%$ \\
\hline & Total & 3158 & $100 \%$ & - \\
\hline \multirow{3}{*}{ Bonus Scheme } & No & 1457 & $46 \%$ & $46 \%$ \\
\hline & Yes & 1701 & $54 \%$ & $100 \%$ \\
\hline & Total & 3158 & $100 \%$ & - \\
\hline \multirow{4}{*}{ ICO Rating } & $0-2,9$ & 683 & $22 \%$ & $22 \%$ \\
\hline & $3-3,9$ & 1558 & $49 \%$ & $71 \%$ \\
\hline & $4-5$ & 917 & $29 \%$ & $100 \%$ \\
\hline & Total & 3158 & $100 \%$ & - \\
\hline & 2017 & 416 & $13 \%$ & $13 \%$ \\
\hline & 2018 & 2138 & $68 \%$ & $81 \%$ \\
\hline ICO Year & 2019 & 597 & $19 \%$ & $100 \%$ \\
\hline & 2020 & 7 & $0 \%$ & $100 \%$ \\
\hline & Total & 3158 & $100 \%$ & - \\
\hline
\end{tabular}
codification represents is also shown as well as the cumulative percentage.

\subsection{Econometric Model}

We have regressed three models with three different dependent variables and which are measures of a project's success, namely, a binary variable asserting the projects' achievement of the soft-cap threshold, a logarithmic variable of the percentage of obtained capital above the soft-cap 
threshold and the logarithmic variable of the capital raised amount. The methods used were a logistic method for the first model and a robust regression for the remaining two models as described in the Methodology section. For the models regressed with a robust regression, we have previously used the standard OLS method in order to compare the results[2]. We confirm that the results along the models are almost identical.

Adopting three levels of significance of $\left.\left.0.01{ }^{(* \star}\right), 0.05^{(* *}\right)$ and $0.1\left(^{*}\right)$ there are seven team variables considered statistically significant. As well as the results in the correspondence analysis we confirm that the projects located in Europe and Asia-Pacific tend to be more successful than projects in other locations. The network effect is also confirmed in our analysis once there is a positive coefficient for the variable Linkedln connections, accepted in all models with the highest significance level, meaning that larger Linkedln networks have a positive effect on the project's success. The variable team rating is also accepted in all models with the highest significance level and shows a positive coefficient which leads us to the conclusion that the rating attributed to the team has also a positive effect on project's success as a measure of teams' quality, experience and cohesion. The same scenario happens with the variable measuring the teams' size by the number of elements composing a team. As in the correspondence analysis, larger teams are connected with more successful projects. Given the conflicting findings in the literature on the impact of team size in the success of a project, we have decided to perform a further analysis by conducting a new regression of the three models which included the squared variable of team size. This analysis would allow us to find a U-shaped curve relationship (Jin, et al., 2017). Although we have obtained a negative coefficient for the squared variable of team size, this revealed not significant which compromises the validity of this hypothesis. Therefore, a U-shaped relationship concerning the team size was not found. We have also included the advisors within the project's team due to their importance for the project and because they represent a small percentage of our sample. Regressing the three models separating the advisors from the project's team, we have found that the new variable measuring only the number of project's team elements maintains the previous results as the one including advisors, in terms of coefficient and statistical significance across all the models. Having in mind the table 7 , the new variable which accounts for the number of advisors in a project, only is considered statistically significant in model 4 . This is due to the small percentage of advisors in the sample used, specifically, there are 565 advisors in the total sample of 3158 . Furthermore, we have regressed the econometric models only using the variable which accounts for the projects' team members without advisors. The results kept robust and consistent with the ones previously obtained. The variable related with the project's vision rating, which we attribute to the team once the vision should come from it, is considered to be statistically significant although with a pronounced negative impact on projects' success. There are two different arguments on this: (i) the better the project's vision, the most successful it should be (Kaplan, Sensoy, \& Stromberg, 2009); (ii) highly disruptive visions are difficult to perceive and implement and thus tend to have a negative impact in project's success (Gompers \& Lerner, 2001). In the ICO market the second argument is even more pronounced due to the technological and disruptive projects involved which jeopardizes project's success despite the disruptive vision (Momtaz, 2020a). Nonetheless, we could not confirm the effects of all the team variables proposed. The variable measuring the number of projects per person is not significant due to the fact that the great majority of the profiles participated only in one project. Although we have found a tendency in the correspondence analysis concerning the variables related with profiles' professional experience, education level and type of academic degree, they all showed not significant in our econometric analysis. Professional experience does not necessarily means expertise (Frese \& Rauch, 2001) and our data confirms this as more experienced professionals have equal chances of success (Sonnentag, 1995). Concerning the level of education, we find this variable not significant as the large majority of the profiles have education at university level, namely, bachelor's degree (1662) and master's degree (1250). Only 61 profiles have less than a bachelor's degree. Therefore, we find that the sample is very homogenous regarding this variable and thus we could not differentiate between successful and unsuccessful profiles on this point. Consequently, we also assumed that a specific level of expertise is needed to participate in ICO projects due to the complex concepts behind it. Nevertheless, this expertise is not captured by the type of academic degree (i.e. technology of business degree) but rather by other variables such as the ratings attributed to the project and to the team. The remaining control variables, focused on the project itself and not on the profiles' characteristics, also showed significance across all models except for the variable token price which is not accepted in the second model and the variables soft-cap limit and currencies accepted which are not accepted in the last model.

Table 7 - Logit and robust regressions 


\begin{tabular}{|c|c|c|c|c|c|c|c|c|c|c|c|c|}
\hline & \multicolumn{2}{|c|}{$\begin{array}{c}\text { Model } 1 \\
\text { Logit Regression } \\
\text { Soft-cap achieved }\end{array}$} & \multicolumn{2}{|c|}{$\begin{array}{c}\text { Model } 2 \\
\text { Logit Regression } \\
\text { Soft-cap achieved }\end{array}$} & $\begin{array}{r}\text { Mc } \\
\text { Robust } \\
\text { Log capital rai }\end{array}$ & $\begin{array}{l}\text { I } 3 \\
\text { ression } \\
\text { over soft-cap }\end{array}$ & $\begin{array}{r}\mathrm{M} \\
\text { Robust } \\
\text { Log capital ra }\end{array}$ & $\begin{array}{l}4 \\
\text { ression } \\
\text { over soft-cap }\end{array}$ & $\begin{array}{r}\text { Mo } \\
\text { Robust R } \\
\text { Log capi }\end{array}$ & $\begin{array}{l}\text { el } 5 \\
\text { egression } \\
\text { al raised }\end{array}$ & $\begin{array}{r}\text { Mo } \\
\text { Robust } \\
\text { Log cap }\end{array}$ & $\begin{array}{l}\text { el } 6 \\
\text { gression } \\
\text { al raised }\end{array}$ \\
\hline $\mathrm{R} 2$ & \multicolumn{2}{|c|}{0.06} & \multicolumn{2}{|c|}{0.161} & \multicolumn{2}{|c|}{0.10} & \multicolumn{2}{|c|}{0.19} & \multicolumn{2}{|c|}{0.09} & \multicolumn{2}{|c|}{0.21} \\
\hline Adjusted R2 & \multicolumn{2}{|c|}{-} & \multicolumn{2}{|c|}{-} & \multicolumn{2}{|c|}{0.10} & \multirow{2}{*}{\multicolumn{2}{|c|}{$\begin{array}{c}0.19 \\
3158\end{array}$}} & \multicolumn{2}{|c|}{0.09} & \multicolumn{2}{|c|}{0.20} \\
\hline \multirow[t]{2}{*}{ Observations } & \multicolumn{2}{|c|}{3158} & \multicolumn{2}{|c|}{3158} & \multicolumn{2}{|c|}{3158} & & & \multicolumn{2}{|c|}{3158} & \multicolumn{2}{|c|}{3158} \\
\hline & Coeficient & Strd. Error & Coeficient & Strd. Error & Coeficient & Strd. Error & Coeficient & Strd. Error & Coeficient & Strd. Error & Coeficient & Strd. Error \\
\hline Team Varibales & & & & & & & & & & & & \\
\hline Number of Projects per Person & -0.04 & 0.03 & -0.03 & 0.03 & 0.00 & 0.00 & 0.00 & 0.00 & -0.08 & 0.05 & -0.07 & 0.05 \\
\hline Location: North America & 0.34 & $0.16^{* *}$ & 0.16 & 0.17 & 0.05 & $0.02 * * *$ & 0.05 & $0.02^{* *}$ & 0.78 & $0.27^{* * *}$ & 0.39 & 0.25 \\
\hline Location: Europe & 0.42 & $0.14^{* * *}$ & 0.34 & $0.15^{* *}$ & 0.05 & $0.02 * * *$ & 0.03 & $0.02 *$ & 0.83 & $0.24 * * *$ & 0.56 & $0.22 * *$ \\
\hline Location: Asia & 0.49 & $0.15^{* * *}$ & 0.51 & $0.16 * * *$ & 0.08 & $0.02 * * *$ & 0.06 & $0.02^{* * *}$ & 1.15 & $0.26 * * *$ & 1.00 & $0.23 * * *$ \\
\hline Linkedln Connections & 0.03 & $0.01 * * *$ & 0.03 & $0.01 * * *$ & 0.00 & $0.00 * * *$ & 0.00 & $0.00 * * *$ & 0.05 & $0.01 * * *$ & 0.04 & $0.01^{* * *}$ \\
\hline Managerial Experience & 0.07 & 0.09 & 0.00 & 0.09 & 0.01 & 0.01 & 0.00 & 0.01 & 0.13 & 0.15 & 0.00 & 0.14 \\
\hline Technology Experience & 0.05 & 0.10 & -0.03 & 0.11 & 0.01 & 0.01 & 0.00 & 0.01 & -0.01 & 0.17 & -0.14 & 0.15 \\
\hline School Degree Rate & 0.05 & 0.06 & 0.06 & 0.06 & 0.01 & 0.01 & 0.01 & 0.01 & 0.15 & 0.10 & 0.14 & 0.09 \\
\hline Business Degree & 0.13 & 0.08 & 0.13 & 0.09 & 0.01 & 0.01 & 0.01 & 0.01 & 0.13 & 0.14 & 0.06 & 0.13 \\
\hline Technology Degree & -0.09 & 0.09 & -0.06 & 0.09 & 0.00 & 0.01 & 0.00 & 0.01 & -0.16 & 0.15 & -0.06 & 0.14 \\
\hline Team Rating & 0.56 & $0.07^{* * *}$ & 0.42 & $0.08^{* * *}$ & 0.10 & $0.01 * * *$ & 0.10 & $0.01 * * *$ & 1.02 & $0.13^{* * *}$ & 0.70 & $0.12^{* * *}$ \\
\hline Vision Rating & -0.30 & $0.08^{* * *}$ & -0.43 & $0.09 * * *$ & -0.07 & $0.01 * * *$ & -0.09 & $0.01 * * *$ & -0.45 & $0.13^{* * *}$ & -0.74 & $0.13^{* * *}$ \\
\hline Number of Team Elements & 0.03 & $0.00 * * *$ & 0.04 & $0.00 * * *$ & 0.01 & $0.00^{* * *}$ & 0.00 & $0.00 * * *$ & 0.06 & $0.01 * * *$ & 0.05 & $0.01^{* * *}$ \\
\hline Control Variables & & & & & & & & & & & & \\
\hline Soft-Cap Limit & & & -0.28 & $0.11^{* * *}$ & & & 0.08 & $0.01 * * *$ & & & 0.24 & 0.15 \\
\hline Hard-Cap Limit & & & 1.05 & $0.17^{* * *}$ & & & 0.05 & $0.02^{* * *}$ & & & 1.09 & $0.23^{* * *}$ \\
\hline Token Price & & & 0.00 & $0.00 * *$ & & & 0.00 & 0.00 & & & 0.00 & $0.00^{* * *}$ \\
\hline Currencies Accepted & & & -0.10 & $0.02 * * *$ & & & -0.01 & $0.00 * * *$ & & & 0.02 & 0.03 \\
\hline Ethereum Platform & & & 0.78 & $0.13^{* * *}$ & & & 0.05 & $0.01 * * *$ & & & 0.76 & $0.18^{* * *}$ \\
\hline Bonus Scheme & & & 0.36 & $0.09 * * *$ & & & 0.02 & $0.01 *$ & & & 0.30 & $0.13^{* *}$ \\
\hline ICO Rating & & & 0.50 & $0.08^{* * *}$ & & & 0.04 & $0.01 * * *$ & & & 0.93 & $0.11^{* * *}$ \\
\hline ICO Year & & & -1.13 & $0.08^{* * *}$ & & & -0.11 & $0.01 * * *$ & & & -1.98 & $0.11^{* * *}$ \\
\hline
\end{tabular}

Significance levels: $p<0.01\left({ }^{* * *}\right) ; p<0.05(* *) ; p<0.1\left(^{*}\right)$

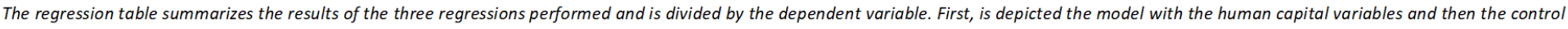

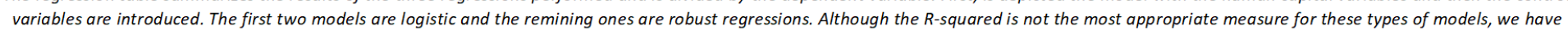
introduced it due to its universality and easy interpretation.

[1] Detailed results available upon request to the authors.

[2] Detailed results available upon request to the authors.

7. Conclusions And Discussion

\subsection{Results discussion}

The ICO projects have been gaining importance due to their novelty (OECD, 2019) but also due to the capital amounts involved in the projects (Coinschedule, 2020) and also due to the regulation challenges they pose (Dostov et al., 2019). The hype verified around the ICOs topic had a peak in the years of 2017 and 2018 (Google, 2020) mainly due to the valorization of the cryptocurrencies (Fisch, 2019). Nevertheless, the ICO projects are extremely innovative and digital (Kranz et al., 2019) and will disrupt the investment world with their characteristics which can be also adopted by more traditional financing models. The ICOs have been compared to other types of financing such as crowdfunding, venture capital or IPOs but they have unique characteristics which distinguish them largely from other forms of financing projects (OECD, 2019). Nonetheless, due to some similarities, the literature has also applied theory and methods related with crowdfunding to ICO projects (Fisch, 2019). The importance of the human capital in the ICO projects is not minor and is taken as having a great importance in the success of a project (An et al., 2019). We were able to capture several teams' characteristics with the variables collected from our database, namely, education, professional experience, number of team elements, networks and social media. In line with research that states the importance of large teams (Giudici \& Adhami, 2019), we also confirm that larger teams have better chances of success. Although we have tried to find the existence of a U-shaped relationship (Jin, et al., 2017), this proved not statically significant. On the opposite, the disruptive vision of the projects, particularly exacerbated in ICO projects, has a negative impact on their success once it may become difficult to perceive and implement (Momtaz, 2020a). Determinants such as team members' education or professional experience are considered not relevant determining the success of a project (Giudici \& Adhami, 2019) which was also confirmed by our analysis going on the opposite direction of studies performed on crowdfunding (Allison et al., 2017) or entrepreneurship (Burton et al., 2002). In addition, our analysis has included variables controlling for the profiles' location, which have revealed to be significant, as well as variables controlling for ratings attributed to the team with the same result. We also conclude that the number of projects in which a person has participated is not relevant in our study. In terms of success' measure, our study confirms that the results are very similar regardless of the independent variables selected and they can be confidently used in order to estimate a project's successful outcome.

\subsection{Theoretical contributions}


We have performed a literature review with the main topics currently discussed on the ICO projects complemented by a market snapshot which captures the main market characteristics in complement to the academic research. We have added our contribution to the research done on ICO projects since we studied the impact of some teams' characteristics to the success of a project. For future research these variables should be considered and included in models trying to measure a project's success. Furthermore, theories applied to these projects should also account for the importance of the human capital in a project success. Concerning the human capital theory, we have confirmed that human capital characteristics are important contributors for ICO project's success. Nevertheless, our data confirms that characteristics such as professional experience might not be the best signalers of human capital quality and might not be good predictors of successful projects since they do not necessarily mean expertise (Sonnentag, 1995). As university degrees are common in our database, they tend to be not relevant and other variables such as networks gain importance in these kinds of projects. The location variables seem to become also important for the project success since they may represent the proximity to open markets with larger availability of capital. Furthermore, human capital theory should consider the role of larger and diversified teams' contribution to the successful outcome of ICO projects. The study developed by An et al., (2019) also addresses the characteristics of the ICOs impacting their success, including human capital characteristics. Nevertheless, we believe there are substantial differences between our research and the one mentioned which make both studies unique. We have used An et al., (2019) in our literature review and the differences we have identified between our study and theirs are the following: i) our study is dedicated to a specific industry, namely banking/financing area, since there are proof that different industries have different outcomes and thus, they must be separated in order to obtain clearer results (Davies \& Giovannetti, 2018; Hartmann et al., 2019); ii) their database is mainly composed by projects outside Europe. Our database has several projects located in Europe but also a representation of other world's regions, for instance, Africa, South America and Middle East, which is very small or non-existent in An et al., (2019); iii) we include other variables in the models such as location, third party ratings or experience and several control variables not included in An et al., (2019), such as, currencies accepted, ICO year or the existence of fundraising goals; iv) we have included 3 different dependent variables in order to test which one would better represent a project's success and to control for different results using different dependents.

\subsection{Managerial implications}

Investing in ICO projects is a highly risky investment which can provide enormous return but also requires enormous attention and due diligence from investors in order to maximize and secure their gains. We have stated the main characteristics of ICOs and the current state of the art in terms of academic research complemented by the market volumes and investment areas of ICO projects in the market snapshot. When investors perform due diligence on a project, they should also look for teams' characteristics once they are related with the successful outcome of the project (Giudici \& Adhami, 2019). Particularly, the human capital characteristics should be considered as important to determine the success of a project (Unger et al., 2011). Based on our data, the investors and managers should consider that professional experience does not always mean expertise since the best professionals might not always be the most experienced (Sonnentag, 1995). Furthermore, we conclude that there is a certain level of expertise needed to participate in ICO projects as the great majority of the team members have a university degree. Nevertheless, this level of expertise is not ascertained by the level of education since most people should have a high degree. The expertise is also not determined by the type of degree (i.e. technologic or business) but rather by other variables such as ratings attributed by external parties. Besides, we conclude that the ratings attributed to the team are also important in order to ascertain the projects' future performance.

\subsection{Research limitations}

The database is composed of profiles who developed projects in the banking/financial services sector. Thus, a limitation of this research is that the conclusions taken were based on projects in only one sector while they would eventually be more robust if the database included more areas although our conclusions are in line with the already existent literature. Furthermore, the data was collected from different data sources, combined and treated manually which involves a degree of human error. We have cross-checked the information several times and have performed consistency controls, but we cannot exclude some bias in our research. Besides, the data collected from ICOBench and Linkedln is generally uploaded to these websites manually based on information provided by projects' promoters which may, at some extent, compromise the integrity of the information (Momtaz, 2019) although there is no obvious reason to doubt it. A further limitation concerns the data regarding ratings used in the econometric models. As previously mentioned, the ratings were collected from ICOBench website and can range from 0 to 5 . These ratings are attributed based on the algorithm developed by the website and the contributions of experts previously certified. As traditional ratings, these ones are dynamic which means that they can vary constantly along the project's lifecycle too. Although the ratings try to be as unbiased as possible, their dynamism means that a project's evaluation can change after the ICO campaign. For instance, even though a rating has a historical component, it can be improved if evaluated by an expert after the project obtains a large amount of funds in the fundraising campaign. Therefore, the ratings obtained and used in this study seem to be a strong indicator of the quality of the project and very important tools for investors in the secondary market, but their impacts can be sometimes inflated due to the constraints already mentioned.

\subsection{Avenues for future research}


We have performed an analysis focused on the impact of teams' characteristics on the projects' success which contributes to fill in a gap in the current literature. Although there are already some studies on ICOs' success, further investigation and new databases should be applied to this intent. We have concluded that human capital is important to the project's success but we still think that a comparative analysis on the importance of human capital along several ways of financing would be important, namely, ICO, crowdfunding and venture capital (Fisch, 2019). We would like to stress also the importance of cryptocurrencies to the ICO projects and their valorization might influence the projects' capital raised. Therefore, a deeper analysis on this topic would be interesting. Testing how token-types affect ICO success also merits future research. The regulation on ICOs is still not extensive and a future research on the regulation already done and future paths would be interesting (Boreiko \& Risteski, 2019; Zhang et al., 2020). Another research topic could be understanding the impacts of regulation on projects' success: does a more regulated project performs better than an unregulated one? The whitepaper's importance should also be deeply addressed in the future in order to understand their similarities

with regulated prospectus and new ways to regulate this important document. Concerning the size of the teams, it would be important to determine the causes of larger teams in an ICO project, in other words, why do ICO teams tend to be composed by a large number of elements? Are there any correlations between the experience and education of the team members and do these factors interact with the team size? Does the demographic diversity of ICO projects' team impacts their success?

\section{Declarations}

Competing interests: The authors declare no competing interests.

\section{Bibliography}

\section{Journal Article}

Adhami, S., \& Guegan, D. (2019). Crypto assets: the role of ICO tokens within a well-diversified portfolio. Journal of Industrial and Business Economics 47:219-241. https://doi.org/10.1007/s40812-019-00141-x

Allison, T. H., Davis, B. C., Webb, J. W., \& Short, J. C. (2017). Persuasion in crowdfunding: An elaboration likelihood model of crowdfunding performance. Journal of Business Venturing 32(6):707-725. http://dx.doi.org/10.1016/j.jbusvent.2017.09.002

An, J., Duan, T., Hou, W., \& Xu, X. (2019). Initial Coin Offerings and Entrepreneurial Finance: The Role of Founders' Characteristics. The Journal of Alternative Investments 21(4):26-40. https://doi.org/10.3905/jai.2019.1.068

Bates, T. (1985). Entrepreneur Human Capital Endowments and Minority Business Viability. The Journal of Human Resources 20(4):540-554. https://doi.org/10.2307/145683

Baum, J. A., \& Silverman, B. S. (2004). Picking winners or building them? Alliance, intellectual, and human capital as selection criteria in venture financing and performance of biotechnology startups. Journal of Business Venturing 19(3):411-436. https://doi.org/10.1016/S08839026(03)00038-7

Becker, G. S. (1994). Human Capital: A Theoretical and Empirical Analysis with Special Reference to Education. The University of Chicago Press.

Benedetti, H., \& Kostovetsky, L. (2021). Digital Tulips? Returns to Investors in Initial Coin Offerings. Journal of Corporate Finance, $66,1-54$. doi:https://dx.doi.org/10.2139/ssrn.3182169

Biasi, J., \& Chakravorti, S. (2019). The Future of Cryptotokens. Disruptive Innovation in Business and Finance in the Digital World 20:167-187. https://doi.org/10.1108/S1569-376720190000020018

Block, J. H., Groh, A., Hornuf, L., Vanacker, T., \& Vismara, S. (2020). The entrepreneurial finance markets of the future: a comparison of crowdfunding and initial coin offerings. Small Business Economics. https://doi.org/10.1007/s11187-020-00330-2

Boone, C., \& Hendriks, W. (2009). Top Management Team Diversity and Firm Performance: Moderators of Functional-Background and Locus-ofControl Diversity. Management Science 55:165-180. https://www.jstor.org/stable/40539137

Boreiko, D., \& Risteski, D. (2019). Serial and Large Investors in Initial Coin Offerings. SSRN. https://dx.doi.org/10.2139/ssrn.3318781

Boreiko, D., Ferrarini, G., \& Giudici, P. (2019). Blockchain Startups and Prospectus Regulation. European Business Organization Law Review 20:591595. https://doi.org/10.1007/s40804-019-00166-8

Brochado, A. (2018a). Snapshot da Indústria das Criptomoedas. (CMVM, Ed.) Caderno do Mercado de Valores Mobiliários 59:83-108. https://www.cmvm.pt/pt/EstatisticasEstudosEPublicacoes/CadernosDoMercadoDeValoresMobiliarios/Documents/Cadernos\%20MVM\%2059\%20\%20VF.pdf 
Brochado, A. (2018b). Snapshot das Initial Coin Offerings (ICOs). (CMVM, Ed.) Cadernos do Mercado de Valores Mobiliários 64:53-76. https://www.cmvm.pt/pt/EstatisticasEstudosEPublicacoes/CadernosDoMercadoDeValoresMobiliarios/Documents/CMVM-CADERNOS-n64.pdf

Bruderl, J., Preisendorfer, P., \& Ziegler, R. (1992). Survival Chances of Newly Founded Business Organizations. American Sociological Review 57(2):227-242. https://doi.org/10.2307/2096207

Brush, C., Greene, P., \& Hart, M. (2001). From initial idea to unique advantage: the entrepreneurial challenge of constructing a resource base. Academy of Management Executive 30(1):64-78. 10.1109/EMR.2002.1022409

Burton, M. D., Sørensen, J. B., \& Beckman, C. M. (2002). Coming From Good Stock: Career Histories and New Venture Formation. Research in the Sociology of Organizations 19:229-262.

Chen, R. R., \& Chen, K. (2020). A 2020 perspective on "Information asymmetry in initial coin offerings (ICOs): Investigating the effects of multiple channel signals". Electronic Commerce Research and Applications 40. https://doi.org/10.1016/j.elerap.2020.100936

Chen, Y. (2018). Blockchain tokens and the potential democratization of entrepreneurship and innovation. Business Horizons 61(4):567-575. https://doi.org/10.1016/j.bushor.2018.03.006

Chiu, I. H., \& Greene, E. F. (2019). The Marriage of Technology, Markets and Sustainable (and) Social Finance: Insights from ICO Markets for a New Regulatory Framework. European Business Organization Law Review 20:139-169. https://doi.org/10.1007/s40804-019-00138-y

Davis, S., Diemers, D., Arslanian, H., Dobrauz, G., Wohlgemuth, L., Perfall, A., Perdrizat, M. (2019). 5th ICO/STO Report. PWC. https://www.pwc.ch/en/publications/2019/ch-PwC-Strategy\&-ICO-Report-Summer-2019.pdf

Davies, W. E., \& Giovannetti, E. (2018). Signalling experience \& reciprocity to temper asymmetric information in crowdfunding evidence from 10,000 projects. Technological Forecasting \& Social Change 133:118-131. https://doi.org/10.1016/j.techfore.2018.03.011

Delivorias, A. (2017). Crowdfunding in Europe: Introduction and state of play. European Parliamentary Research Service. https://www.europarl.europa.eu/RegData/etudes/BRIE/2017/595882/EPRS_BRI(2017)595882_EN.pdf

Dostov, V., Shust, P., Leonova, A., \& Krivoruchko, S. (2019). "Soft law" and innovations: empirical analysis of ICO-related statements. Digital Policy, Regulation and Governance 21(5):476-493. https://doi.org/10.1108/DPRG-03-2019-0018

Fabricant, S. (1959). Basic Facts on Productivity Change. National Bureau of Economic Research.

Fisch, C. (2019). Initial coin offerings (ICOs) to finance new ventures. Journal of Business Venturing: 34(1):1-22.

https://doi.org/10.1016/j.jbusvent.2018.09.007

Foley, S., Karlsen, J. R., \& Putninšs, T. J. (2018). Sex, Drugs, and Bitcoin: How Much Illegal Activity Is Financed Through Cryptocurrencies? Review of Financial Studies. https://dx.doi.org/10.2139/ssrn.3102645

Frese, M., \& Rauch, A. (2001). Psychology of Entrepreneurship. (Elsevier, Ed.) International Encyclopedia of the Social \& Behavioral Sciences 1:4552-4556. 10.1146/annurev-orgpsych-031413-091326

Giudici, G., \& Adhami, S. (2019). The impact of governance signals on ICO fundraising success. Journal of Industrial and Business Economics 46:283-312. https://doi.org/10.1007/s40812-019-00118-w

Goergen, M., \& Rondi, L. (2019). Grand challenges and new avenues for corporate governance research. Journal of Industrial and Business Economics 46:137-146. https://doi.org/10.1007/s40812-019-00117-x

Gompers, P. A., \& Lerner, J. (2001). The money of invention: How venture capital creates new wealth. Harvard Business School Press.

Hornuf, L., Kück, T., \& Schwienbacher, A. (2019). Initial Coin Offerings, Information Disclosure, and Fraud. CESifo Working Paper No. $7962: 1-38$. https://ssrn.com/abstract=3498719

Howell, S., Niessner, M., \& Yermack, D. (2018). nitial Coin Offerings: Financing Growth with Cryptocurrency Token Sales. NBER WORKING PAPER SERIES 1-64. https://ssrn.com/abstract=3206449

Jin, L., Madison, K., Kraiczy, N. D., Kellermanns, F. W., Crook, D. T., \& Xi, J. (2017). Entrepreneurial Team Composition Characteristics and New Venture Performance: A Meta-Analysis. SAGE Journals 743-771. https://doi.org/10.1111/etap.12232

Jong, A. d., Roosenboom, P., \& Kolk, T. v. (2018). What determines success in Initial Coin Offerings? SSRN. http://dx.doi.org/10.2139/ssrn.3250035 
Kaplan, S. N., Sensoy, B. A., \& Stromberg, P. (2009). Should investors bet on the jockey or the horse? Evidence from the evolution of firms from early business plans to public companies. The Journal of Finance 75-115. https://doi.org/10.1111/j.1540-6261.2008.01429.x

Kher, R., Terjesen, S., \& Liu, C. (2020). Blockchain, Bitcoin, and ICOs: a review and research agenda. Small Business Economics. https://doi.org/10.1007/s11187-019-00286-y

Khurshed, A. (2019). Initial Public Offerings: The mechanics and performance of IPOs. Harriman House.

Kranz, J., Nagel, E., \& Yoo, Y. (2019). Blockchain Token Sale: Economic and Technological Foundations. Business and Information Systems Engineering 61:745-753. https://doi.org/10.1007/s12599-019-00598-Z

Larios-Hernández, G. (2017). Blockchain entrepreneurship opportunity in the practices of the unbanked. Business Horizons 60(6):865-874. https://doi.org/10.1016/j.bushor.2017.07.012

Lechler, T. (2001). Social Interaction: A Determinant of Entrepreneurial Team Venture Success. Small Business Economics 16:263-278. https://doi.org/10.1023/A:1011167519304

Liebau, D., \& Schueffel, P. (2019). Cryptocurrencies \& Initial Coin Offerings: Are they Scams? - An Empirical Study. The Journal of British Blockchain Association 2(1):1-7. https://doi.org/10.31585/jbba-2-1-(5)2019

Mamonov, S., \& Malaga, R. (2020). A 2020 perspective on "Success factors in Title III equity crowdfunding in the United States". Electronic Commerce Research and Applications 40. https://doi.org/10.1016/j.elerap.2020.100933

Masiak, C., Block, J. H., Masiak, T., Neuenkirch, M., \& Pielen, K. N. (2018). The Market Cycles of ICOs, Bitcoin, and Ether. https://dx.doi.org/10.2139/ssrn.3198694

Maume, P., \& Fromberger, M. (2019). Regulation of Initial Coin Offerings: Reconciling U.S. and E.U. Securities Laws. Chicago Journal of International Law 19(2). https://chicagounbound.uchicago.edu/cjil/vol19/iss2/5

Meena, S. D., Sriram, M., \& Sundaram, N. (2017). Digital financial inclusion is a need of the hour: An investigation amongst bank account holders in Vellore district of Tamil Nadu, India. International Journal of Applied Business and Economic Research, 15(21):1-6. http:www.serialsjournal.com

Mincer, J. (1958). Investment in Human Capital and Personal Income Distribution. Journal of Political Economy 66(4):281-302.

https://www.jstor.org/stable/1827422

Moedl, M. (2018). Two's a Company, Three's a Crowd: Deal Breaker Terms in Equity Crowdfunding for Prospective Venture Capital. SSRN. https://dx.doi.org/10.2139/ssrn.3284559

Momtaz, P. P. (2019). Entrepreneurial Finance and Moral Hazard: Evidence from Token Offerings. Journal of Business Venturing. https://dx.doi.org/10.2139/ssrn.3343912

Momtaz, P. P. (2020). Initial coin offerings, asymmetric information, and loyal CEOs. Small Business Economics. https://doi.org/10.1007/s11187020-00335-x

Momtaz, P. P. (2020a). Initial Coin Offerings. (N. I. Renuka Sane, Ed.) PLoS ONE. https://doi.org/10.1371/journal.pone.0233018

Nguyen, T., Nguyen, B., Nguyen, T., \& Nguyen, Q. (2019). Bitcoin return: Impacts from the introduction of new altcoins. Research in International Business and Finance 48:420-425. https://doi.org/10.1016/j.ribaf.2019.02.001

Piva, E., \& Rossi-Lamastra, C. (2018). Human capital signals and entrepreneurs' success in equity crowdfunding. Small Business Economics 51:667-686. https://doi.org/10.1007/s11187-017-9950-y

Rohr, J., \& Wright, A. (2019). Blockchain-Based Token Sales, Initial Coin Offerings, and the Democratization of Public Capital Markets. Hastings Law Journal. http://www.hastingslawjournal.org/wp-content/uploads/70.2-Rohr-1.pdf

Schückes, M., \& Gutmann, T. (2020). Why do startups pursue initial coin offerings (ICOs)? The role of economic drivers and social identity on funding choice. Small Business Economics. https://doi.org/10.1007/s11187-020-00337-9

Schultz, T. W. (1961). Investment in Human Capital. The American Economic Review 51(1):1-17. https://www.jstor.org/stable/1818907

Sharma, Z., \& Zhu, Y. (2020). Platform building in initial coin offering market: Empirical evidence. Pacific-Basin Finance Journal 61.

https://doi.org/10.1016/j.pacfin.2020.101318

Page $17 / 21$ 
Sonnentag, S. (1995). Excellent software professionals: experience, work activities, and perception by peers. Behaviour \& Information Technology 14(5):37-41. https://doi.org/10.1080/01449299508914648

Sovbetov, Y. (2018). Factors Influencing Cryptocurrency Prices: Evidence from Bitcoin, Ethereum, Dash, Litcoin, and Monero. Journal of Economics and Financial Analysis 2:1-27. http://dx.doi.org/10.1991/jefa.v2i2.a16

Sweetland, S. R. (1996). Human Capital Theory: Foundations of a Field of Inquiry. Review of Educational Research 66(3):341-359. https://doi.org/10.3102/00346543066003341

Tiwari, M., Gepp, A. \& Kumar, K. (2020). The future of raising finance - a new opportunity to commit fraud: a review of initial coin offering (ICOs) scams. Crime Law Soc Change 73:417-441. 10.1007/s10611-019-09873-2

Ucbasaran, D., Lockett, A., Wright, M., \& Westhead, P. (2003). Entrepreneurial Founder Teams: Factors Associated with Member Entry and Exit. SAGE Journals 28(2):107-128. https://doi.org/10.1046/j.1540-6520.2003.00034.x

Unger, J. M., Rauch, A., Frese, M., \& Rosenbusch, N. (2011). Human capital and entrepreneurial success: A meta-analytical review. Journal of Business Venturing 26(3):341-358. https://doi.org/10.1016/j.jbusvent.2009.09.004

Yeh, J.-Y., \& Chen, C.-H. (2020). A machine learning approach to predict the success of crowdfunding fintech project. Journal of Enterprise Information Management. https://doi.org/10.1108/JEIM-01-2019-0017

Zhang, S., Zhang, D., Zheng, J., \& Aerts, W. (2020). Does policy uncertainty of the blockchain dampen ICO markets? Accounting \& Finance. https://doi.org/10.1111/acfi.12639

Zimmerman, M. A., \& Zeitz, G. J. (2002). Beyond Survival: Achieving New Venture Growth by Building Legitimacy. The Academy of Management Review 27(3) :414-431. https://doi.org/10.2307/4134387

\section{Book Chapter}

Campino, J., Brochado, A., \& Rosa, Á. (2020). Digital Business Transformation in the Banking Sector. In: Dynamic Strategic Thinking for Improved Competitiveness and Performance. IGI Global, pp. 52-88. doi:http://doi:10.4018/978-1-7998-4552-2.ch003

Li, G. (1985). Robust Regression. In: Exploring Data Tables, Trends, and Shapes. John Wiley \& Sons, Inc., USA, pp. 281-341

\section{Conference Proceedings}

Hartmann, F., Grottolo, G., Wang, X., \& Lunesu, M. I. (2019). Alternative Fundraising: Success Factors for Blockchain-Based vs. Conventional Crowdfunding. Blockchain Oriented Software Engineering (IWBOSE), pp. 38-43. https://doi.org/10.1109/IWBOSE.2019.8666515

Spinedi, G., Rigotti, G., Canetta, L., Camoesa, L., \& Redaelli, C. (2019). Guideline for enterprise to a Value Plan through Blockchain and ICO. 2019 IEEE International Conference on Engineering, Technology and Innovation (ICE/ITMC). Valbonne Sophia-Antipolis: IEEE.

10.1109/ICE.2019.8792601

\section{Online Document}

Massey, R., Dalal, D., \& Dakshinamoorthy, A. (2017). Initial Coin Offering: A new paradigm. Deloitte. https://www2.deloitte.com/content/dam/Deloitte/ru/Documents/risk/deloitte-blockchain-initial-coin-offering.pdf. Accessed: 21 January 2021

KPMG. (2019). Regulation and supervision of fintech: Ever-expanding expectations.

https://assets.kpmg/content/dam/kpmg/xx/pdf/2019/03/regulation-and-supervision-of-fintech.pdf. Accessed: 21 January 2021

OECD. (2019). Initial Coin Offerings (ICOs) for SME Financing. http://www.oecd.org/finance/ICOs-for-SME-Financing.pdf. Accessed: 21 January 2021

STATA. (2020a). Stata 16 documentation. https://www.stata.com/manuals13/rsktest.pdf. Accessed: 21 January 2021

STATA. (2020b). Stata 16 documentation. https://www.stata.com/manuals13/rrreg.pdf. Accessed: 21 January 2021

STATA. (2020c). Stata 16 documentation. https://www.stata.com/manuals13/rlogit.pdf. Accessed: 21 January 2021

Williams, R. (2020). Richard Williams, Department of Sociology, University of Notre Dame. https://www3.nd.edu/ rwilliam/stats2/I25.pdf. Accessed: 21 January 2021 


\section{Website}

CoinDance. (2020). CoinDance. https://coin.dance/. Accessed: 21 January 2021

Coinschedule. (2020). Coinschedule. https://www.coinschedule.com/. Accessed: January 222020

Google. (2020). Google Trends. https://trends.google.com/. Accessed: 21 January 2021

ICOBench. (2020). ICO Bench. https://icobench.com. Accessed: 21 January 2021

\section{Figures}

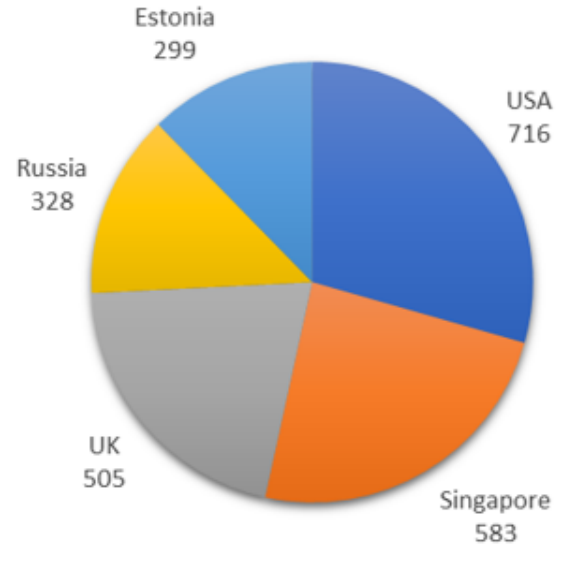

\section{Figure 1}

Countries with the largest number of ICOs

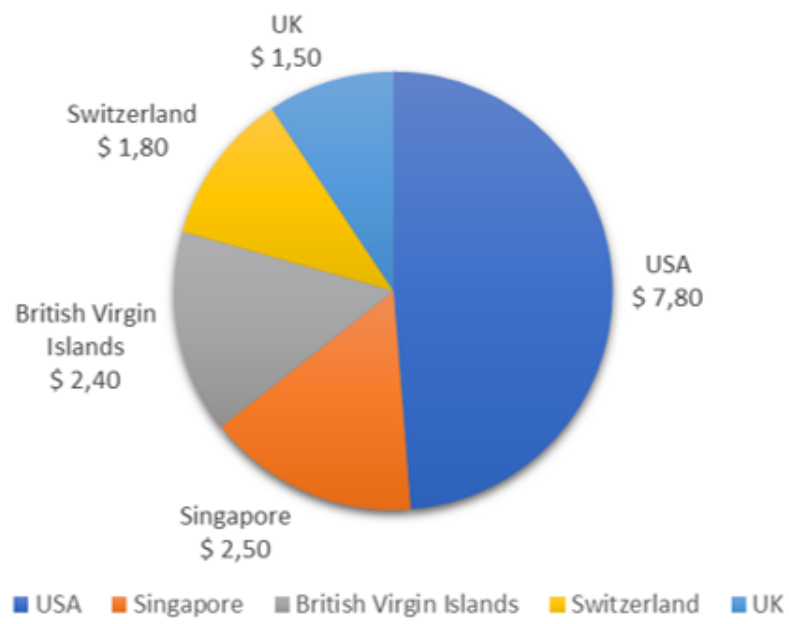

\section{Figure 2}

Amounts raised per country 


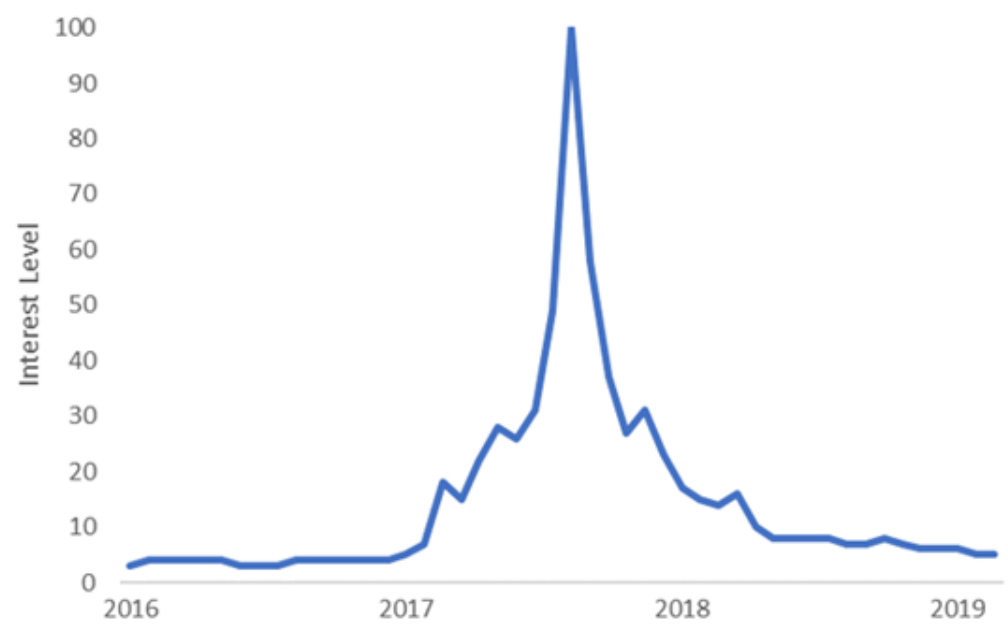

\section{Figure 3}

ICO's level of interest according to Google Trends

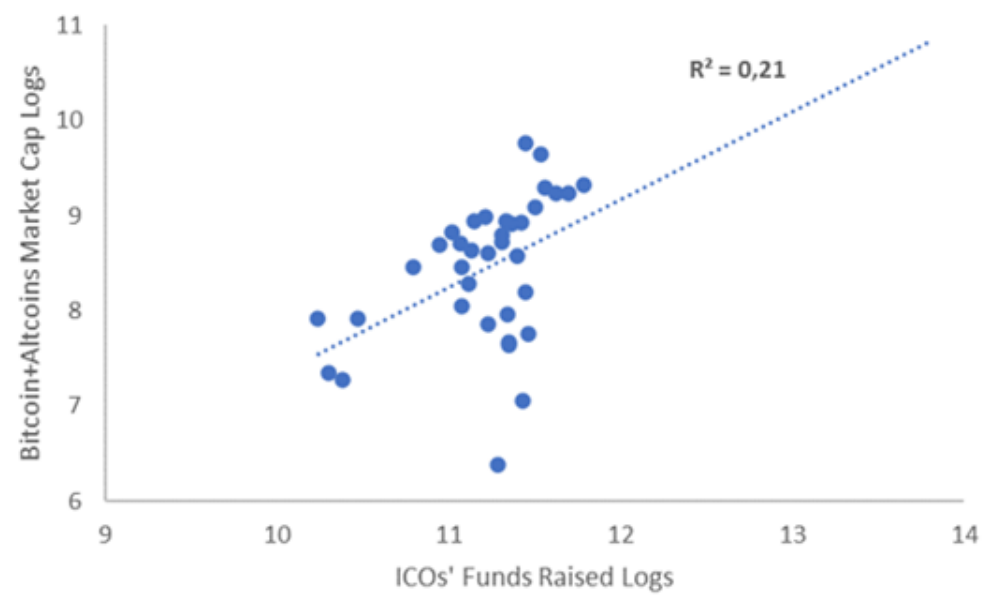

\section{Figure 4}

Correlation between cryptocurrencies' market cap and ICOs' funds raised

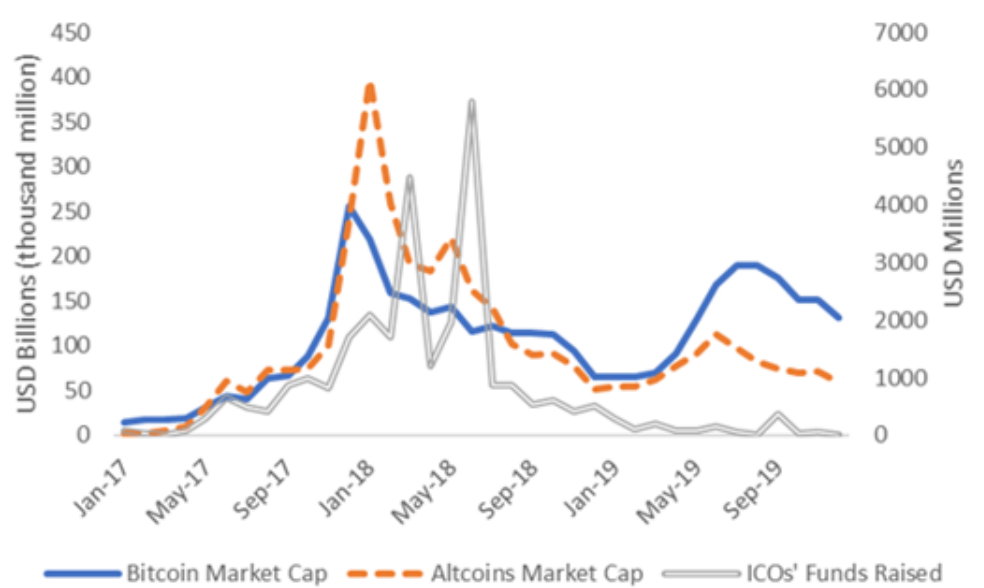

Figure 5 
Cryptocurrencies market cap (left axis) and ICOs' funds raised (right axis)

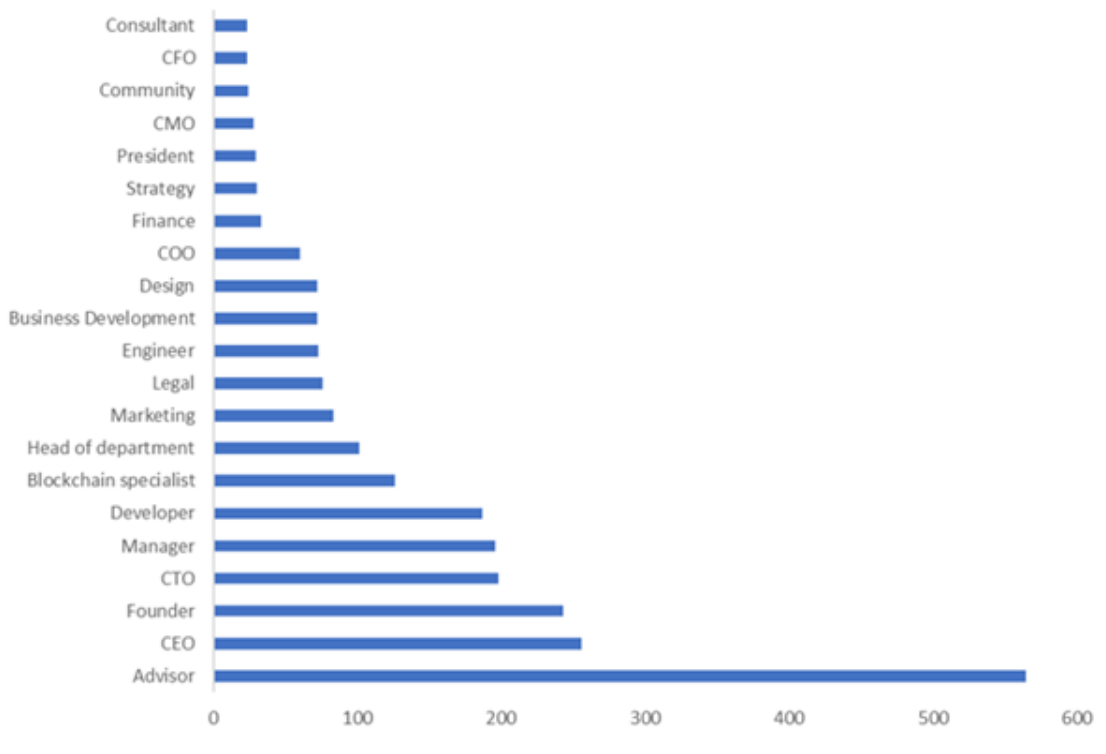

Figure 6

Main functions of ICOs' teams 